Article

\title{
Investigation of the Optimal \\ Omni-Direction-Guide-Vane Design for Vertical Axis Wind Turbines Based on Unsteady Flow CFD Simulation
}

\author{
Behzad Shahizare, Nik Nazri Bin Nik Ghazali *, Wen Tong Chong, Seyed Saeed Tabatabaeikia \\ and Nima Izadyar
}

Department of Mechanical Engineering, Faculty of Engineering, University of Malaya, 50603 Kuala Lumpur, Malaysia; shahizare@siswa.um.edu.my (B.S.); chong_wentong@um.edu.my (W.T.C.);

saeedtk@siswa.um.edu.my (S.S.T.); n.izadyar15@gmail.com (N.I.)

* Correspondence: nik_nazri@um.edu.my; Tel.: +60-379-674-454

Academic Editor: Frede Blaabjerg

Received: 7 December 2015; Accepted: 18 January 2016; Published: 2 March 2016

\begin{abstract}
With soaring energy demands, the desire to explore alternate and renewable energy resources has become the focal point of various active research fronts. Therefore, the scientific community is revisiting the notion to tap wind resources in more rigorous and novel ways. In this study, a two-dimensional computational investigation of the vertical axis wind turbine (VAWT) with omni-direction-guide-vane (ODGV) is proposed to determine the effects of this guide vane. In addition, the mesh and time step $(d t)$ size dependency test, as well as the effect of the different turbulence models on results accuracy are investigated. Eight different shape ratios $(R)$ of the omni-direction-guide-vane were also examined in this study. Further, the CFD model is validated by comparing the numerical results with the experimental data. Validation results show a good agreement in terms of shape and trend in CFD simulation. Based on these results, all the shape ratios, except two ratios including 0.3 and 0.4 at TSR of 1.3 to 3 , have a positive effect on the power and torque coefficient improvement. Moreover, results show that the best case has a shape ratio of 0.55 , which improves the power coefficient by $48 \%$ and the torque coefficient up to $58 \%$.
\end{abstract}

Keywords: vertical axis wind turbine; guide vane; CFD; turbulence model; shape ratio

\section{Introduction}

Typically, wind turbines are classified into two general types based on their axis of rotation: horizontal axis wind turbines (HAWTs) and vertical axis wind turbines (VAWTs). Among these two types, HAWTs are usually better suited for large scale energy generation, while VAWTs are easier to install, omni-directional and better suited for small-scale and micro-scale energy generation projects [1]. With increasing energy generation from off-grid systems and grid supplementation, VAWTs have begun to play a major role in harvesting electricity from wind energy. Vertical axis wind turbines are usually well known to perform potentially better in urban regions compared with horizontal axis wind turbines due to the fact that vertical axis wind turbines do not require alignment to the oncoming flow. In urban regions the wind flow directions are typically continuously changing and this makes vertical axis wind turbines good candidates for harnessing this kind of multidirectional wind flow. The wind flow speed in urban regions is relatively low and also extremely turbulent, which adds extra complexity to the fluid flow structure [2]. The advantages of VAWTs include low noise, better aesthetics for integration into buildings, omni-directionality without a yaw control (less number of parts), less operating cost (the gearbox between rotor and generator is not required) and 
much more efficiency in turbulent environments [3]. Nowadays, It is widely agreed that VAWTs are more effective in urban areas [4,5]. However, VAWTs have also some drawbacks, and possessing a low starting torque, high torque fluctuations and a complex flow are some of the issues which hold back the potential market of VAWTs. To overcome these disadvantages, some studies such as those of Chong et al. [6-9], Oman et al. [10], and Thomas [11], have recently introduced a device named the omni-direction-guide-vane (ODGV).

The complexity of the flow structures in VAWTs and cost of the experimental testing methods have led to an increase in the use of computational fluid dynamics (CFD) to simulate the flow characteristics and performance of VAWTs. Wang et al. [12] have used a barchans dune as a model to design the guide vanes of a wind turbine. They designed a lotus shaped guide vane as a decoration for urban areas. In that study, CFD was used to investigate the effects of different barchans dune skew angles. They also concluded that the use of the lotus shape guide vane could enhance the power coefficients above $120 \%$. Nobile et al. [13] have simulated a VAWT with ODGV in a 2-D model by using an airfoil-shaped ODGV. The results of this study show that the torque and power coefficient could increase by up to $30 \%$ to $35 \%$. In another study, the effect of an unsteady incoming wind on the performance of VAWTs has been investigated by Danao et al. [14]. Almohammadi et al. [15] validated the CFD simulation by using the Grid Convergence Index method, fitting method and mesh independent solution by means of the Richardson Extrapolation method. Pope et al. [16] have conducted experimental and numerical studies to determine the operating performance and power output of the VAWT. In this 2-D model, they used $k-\varepsilon$ turbulence while for the 3-D model; Spalart-Allmaras equations were used. The effects of the guide vanes on the turbine's power output were presented. The simulation predicted a performance improvement of $13.5 \%$ by using the guide vane in the turbine. Takao et al. [17] focused on the different angles and distances between the turbine and the guide vane. These authors claimed that the power coefficient was improved 1.8-fold via a guide vane with an angle of $45^{\circ}$. Furthermore, they concluded that the distance between the turbine and guide vane did not have any effect on the turbine performance. Some other previous studies $[5,8,9,18-25]$ showed that by using a two-dimensional model, it is possible to predict the flow physics around the VAWT. A $k$ - $w$ turbulence model 3-D model was also tested using coarse meshes, but due to the immense computational time requirements, this was considered impractical for this study. However, a review of the previous studies [26-28] shows that 3D simulations based on a $k-e$ model are a suitable and fast method.

Typically, the role of blades has been considered as the most important issue of the previous studies in terms of VAWT; however some studies investigated the impact of geometry impacts via CFD simulation. As an example, the role of the unusual arms has been investigated by De Marco, Agostino, et al. [29]. The results of this study show that more power can be produced via a wind turbine with this structure of the arms. In addition, some other vertical axis turbines (hydro and wind) have been investigated in the previous decade $[30,31]$. These studies scrutinized the mentioned effects on the performance of VAWTs by using different methods.

Regarding a ODGV which has been designed in a previous study [6], the aim of this work was to figure out the effect of ODGV on the VAWT. This ODGV consists of four pairs of straight wall guide vanes, and the VAWT has five vertical blades with two supporting arms and a central shaft. In the first part, CFD simulation on the open rotor VAWT is conducted in order to select the acceptable mesh and time step $(d t)$, and turbulence model. In the next step, the CFD results are validated with the experimental data. In third part, the augmented VAWT is scrutinized and effect of the ODGV on the VAWT is obtained. Finally, the effect of the ODGV shape ratio on the VAWT performance is illustrated. It should be stated that all of the simulations in this study have been performed via the ANSYS Fluent commercial software.

\section{Operation Principles}

The power performance of the VAWT can be explored and presented depending on the various tip-speed ratios (TSR) as below: 


$$
T S R=\frac{\text { Tip speed }}{\text { Wind speed }}=\frac{\omega R_{\text {rotor }}}{U_{\infty}}
$$

where $R_{\text {rotor }}$ represents the rotor radius which is equal to $250 \mathrm{~mm}$ and $\omega$ is the rotational speed which varies from $9.6 \mathrm{rad} / \mathrm{s}$ to $72 \mathrm{rad} / \mathrm{s}$ and $U_{\infty}$ is the relative wind speed.

Tip speed ratio for this study is varied from $T S R=0.393$ (corresponding to the rotor angular velocity $\omega=9.6 \mathrm{rad} / \mathrm{s})$ to $T S R=3(\omega=72 \mathrm{rad} / \mathrm{s})$.

On the other hand, the Reynolds number is:

$$
R e=\frac{c U_{I F}}{v}
$$

where, $c$ is the airfoil chord, $v$ represents air kinematic viscosity at $20^{\circ} \mathrm{C}, U_{I F}$ is the total velocity at the interface which defined by the expression:

$$
U_{I F}^{2}(\theta)=U_{\infty}^{2}+\omega^{2} R_{g}^{2}+2 \omega R_{g} U_{\infty} \cos \theta
$$

where $R_{g}$ is the rotating domain radius, $\theta$ is the azimuth angle which is between $\theta=0^{\circ}$ and $\theta=360^{\circ}$ in one revolution of the turbine. In all range of the assumed TSRs, the Reynolds number is between $R_{e}=4.7 \times 10^{4}$ to $R_{e}=2.5 \times 10^{5}$ which is identified as a low Reynolds regime. Torque coefficient $\left(C_{Q}\right)$ and power coefficient $\left(C_{p}\right)$ have been employed to analyze the results. The power coefficient, denoted by $C_{p}$, is a ratio of the power produced by the wind rotor to the power available at a specific wind speed. These two parameters are defined in Equations (4) and (5), respectively:

$$
\begin{gathered}
C_{Q}=\frac{\text { Torque }}{0.5 \rho U_{\infty}{ }^{2} R_{\text {rotor }} A_{S}} \\
C_{P}=(T S R) C_{Q}
\end{gathered}
$$

where $\rho$ is the air density, $A_{s}$ is the swept area of the turbine, $U_{\infty}$ is the inlet wind velocity and Torque is calculated from CFD simulation or experimental data. Torque is defined in Equation (6):

$$
\vec{T}=\vec{r} \times \vec{F}_{p}+\vec{r} \times \vec{F}_{v}
$$

where $\vec{r}$ is Torque vector, $\vec{F}_{p}$ is pressure force vector and $\vec{F}_{v}$ is viscous force vector . more information about how to calculate the Torque is available in ANSYS Fluent help [32].

Unsteady Reynolds-Averaged Navier-Stokes (RANS) equations have been solved via SIMPLE algorithm for the pressure and velocity coupling. Finite-Volume method with the second-order upwind scheme have been employed for discretization. The Navier-Stokes equations and continuity equation are defined in Equations (7) and (8) respectively:

$$
\begin{gathered}
\rho \frac{D \vec{v}}{D t}=-\nabla P+\mu \nabla^{2} \vec{v} \\
-\nabla \cdot \vec{V}=\frac{\partial u}{\partial x}+\frac{\partial v}{\partial y}+\frac{\partial w}{\partial z}
\end{gathered}
$$

\section{Computational Setup}

\subsection{The VAWT Geometry}

A 3-D model of the VAWT is generated by using the Solid Works CAD software, it is a straight-bladed Darrieus turbine with a rotor diameter of $D_{R}=500 \mathrm{~mm}$. The rotor consists of five blades, and each blade is attached to a central shaft by two supporting arms. Figure 1 shows a 3D model of the VAWT. 


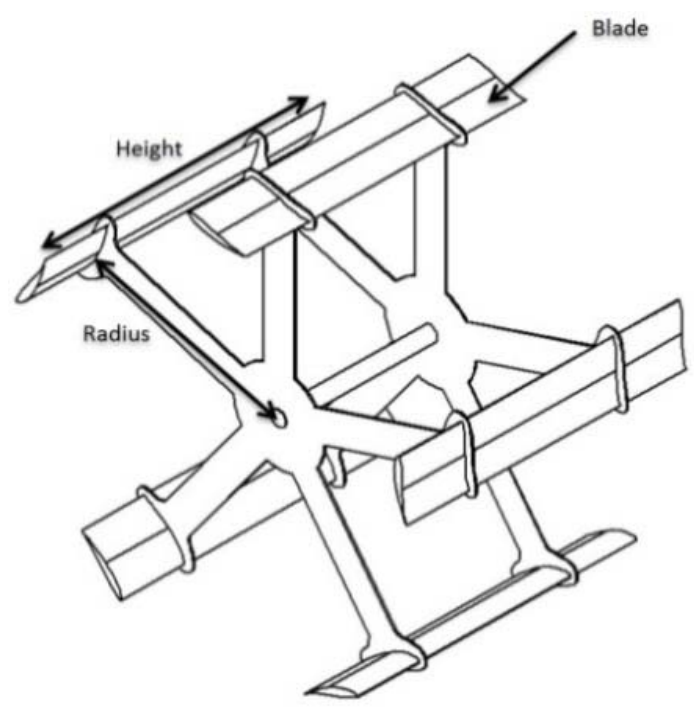

Figure 1. 3-D model of the VAWT.

Generally, in order to reduce the computational time and understand the effect of the ODGV on the VAWT, CFD simulation has been carried out on a 2-D model. This 2-D model was extracted from the middle section of the 3-D model. Therefore, the effect of the supporting arms and central shaft was not considered. The airfoil type in this VAWT is a FX 63-137. The pitch angle of the blades is set as $10^{\circ}$ and the pressure center is located in the midsection of the blades $0.5 c$. The characteristics of the wind turbine and its airfoils are listed in Table 1.

Table 1. Properties of the wind turbine.

\begin{tabular}{cc}
\hline Geometry of Turbine & Dimensions \\
\hline Blade airfoil section & Fx $63-137$ \\
Blade chord $(c)$ & $78 \mathrm{~mm}$ \\
Radius of the turbine $(R)$ & $250 \mathrm{~mm}$ \\
Solidity $(N c / D)$ & 0.78 \\
Max camber & $5.8 \%$ at $56.5 \% \mathrm{c}$ \\
Height $(H)$ & $350 \mathrm{~mm}$ \\
Aspect ratio $(H / D)$ & 1.04 \\
Thickness $(t)$ & $13.75 \mathrm{~mm}$ \\
Peak position $\left(C_{p}\right)$ & $\theta=60^{\circ}$ \\
\hline
\end{tabular}

\subsection{Geometry of $O D G V$}

As mentioned, the base design of the ODGV is considered from the previous study [6]. The ODGV comprises four sets of double straight walls. Figure 2 shows the 3-D model of the ODGV.

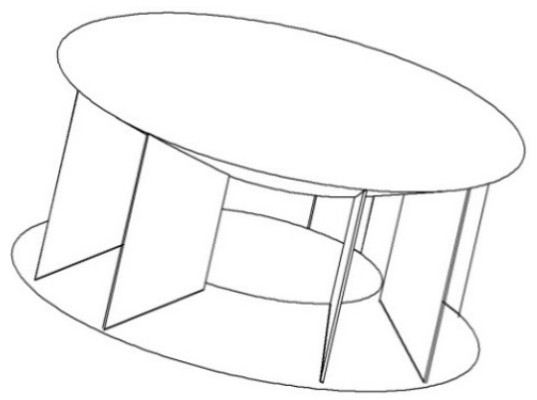

Figure 2. Three-dimensional model of the ODGV. 
The 2-D model design is generated as below (Figure 3):

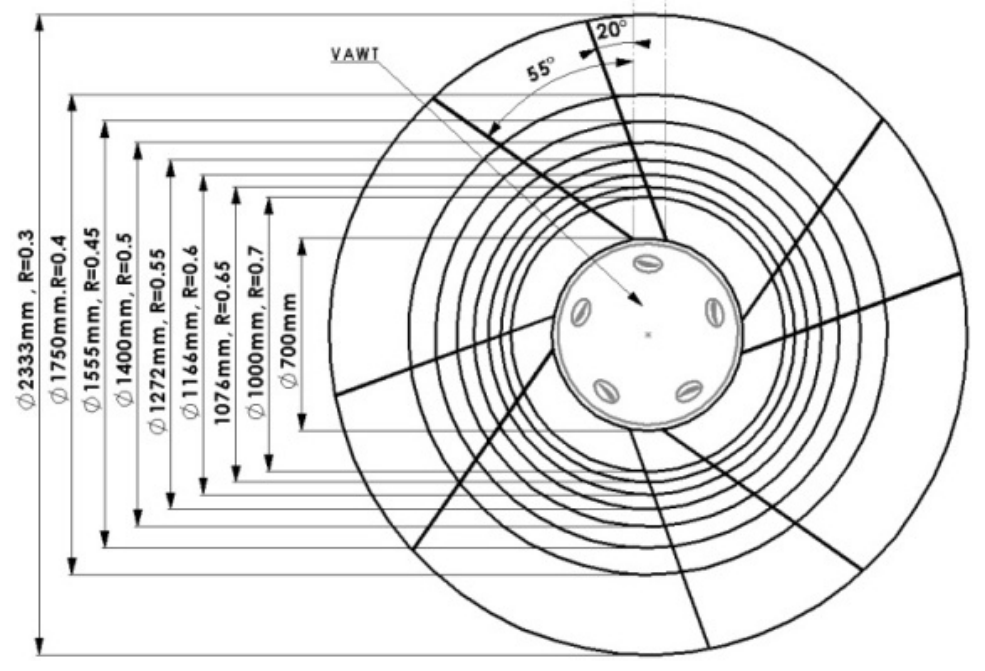

Figure 3. Shape ratio of the ODGV.

As can be seen from Figure 3, eight different shape ratios are investigated. The internal diameter ( $D_{\text {inner }}$ ) is $700 \mathrm{~mm}$ and the external diameter varies between $1000 \mathrm{~mm}$ and $2333 \mathrm{~mm}$. The ODGV width is varied based on shape ratios and it is started from $187 \mathrm{~mm}$ for $R_{\text {shape-ratio }}=0.7$ and reached to $895 \mathrm{~mm}$ for $R_{\text {shape-ratio }}=0.3$. The shape ratio can be defined as below:

$$
R_{\text {shape-ratio }}=\frac{D_{\text {inner }}}{D_{\text {outer }}}
$$

\subsection{The Wind Tunnel Numerical Domain}

Mohamed et al. [33] reported that the size of the wind tunnel affects the variation of rotor power coefficient. In addition, they recommended that the wind tunnel should be extended by at least 10 times the rotor diameter in each direction. Figure 4 indicates the domain of the wind tunnel.

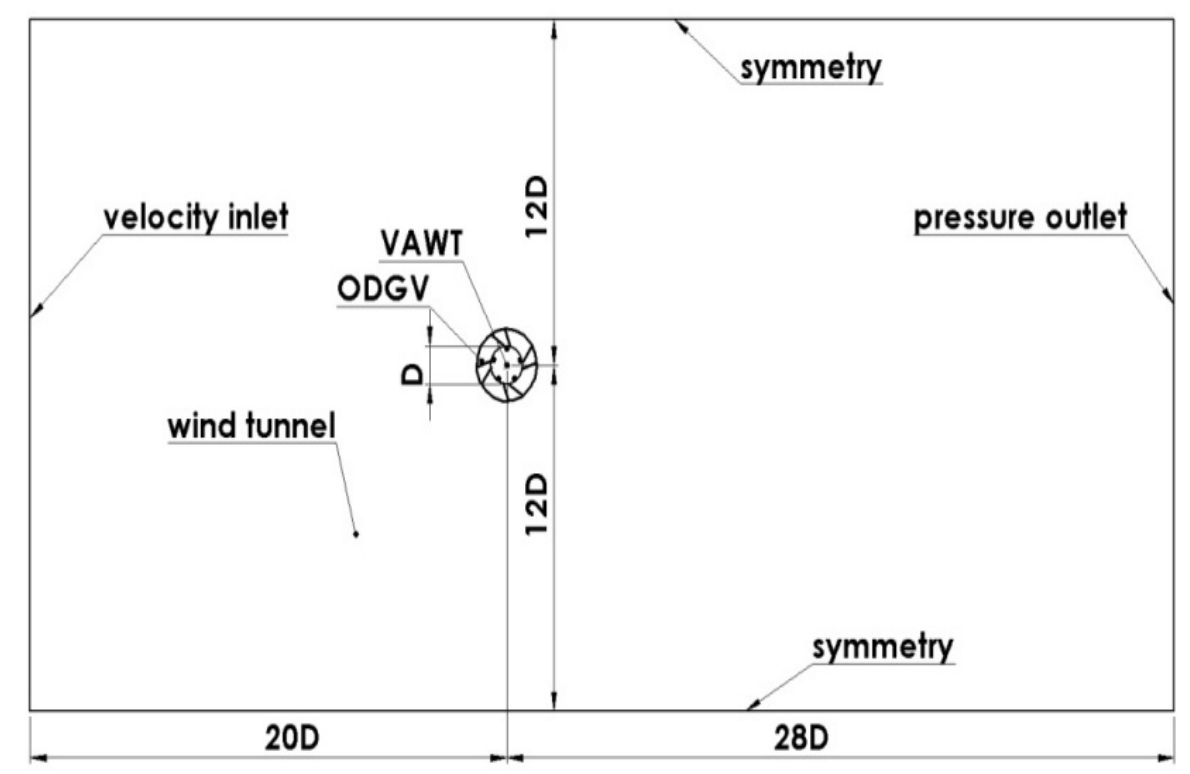

Figure 4. Wind tunnel (domain). 
According to Figure 4, the domain size is 20D from the inlet, 28D from the outlet and 12D from the sides; to avoid solid blockage in test domain. For the primary boundary condition, the inlet is set as a velocity inlet $(6 \mathrm{~m} / \mathrm{s})$ with a constant wind velocity profile of $6 \mathrm{~m} / \mathrm{s}$, while the outlet is set as a pressure outlet (P outlet $=0$ ) with atmospheric pressure value.

Regarding the ratio of wind tunnel frontal area to the test section frontal area, a very small solid blockage effect can be reported, this effect is corrected by Pope \& Harper Blockage Correction equations [34]. The results of wind tunnel test have been obtained based on these corrections as below:

Wind tunnel frontal is $2 \times 1.5=3$.

Test section frontal area $0.5 \times 0.52=0.26$

$$
\epsilon_{t}=\frac{1}{4} \frac{\text { Model Frontal Area }}{\text { Test Section Area }}=0.0216
$$

\subsection{Mesh Generation and Boundaries}

As shown in Figure 4, the 2-D fluid domain is composed of two distinct domains; a fixed rectangular outer domain with a circular aperture; and a circular inner domain to fit into the aperture. The fixed rectangular outer domain is identified as the wind tunnel domain, and the circular inner domain is identified as the rotational domain resembling the wind turbine. To create an accurate mesh around the rotating zone, the inside of the turbine is divided into sub sections. The control ellipses enclosed around the airfoils are depicted in Figure 5.

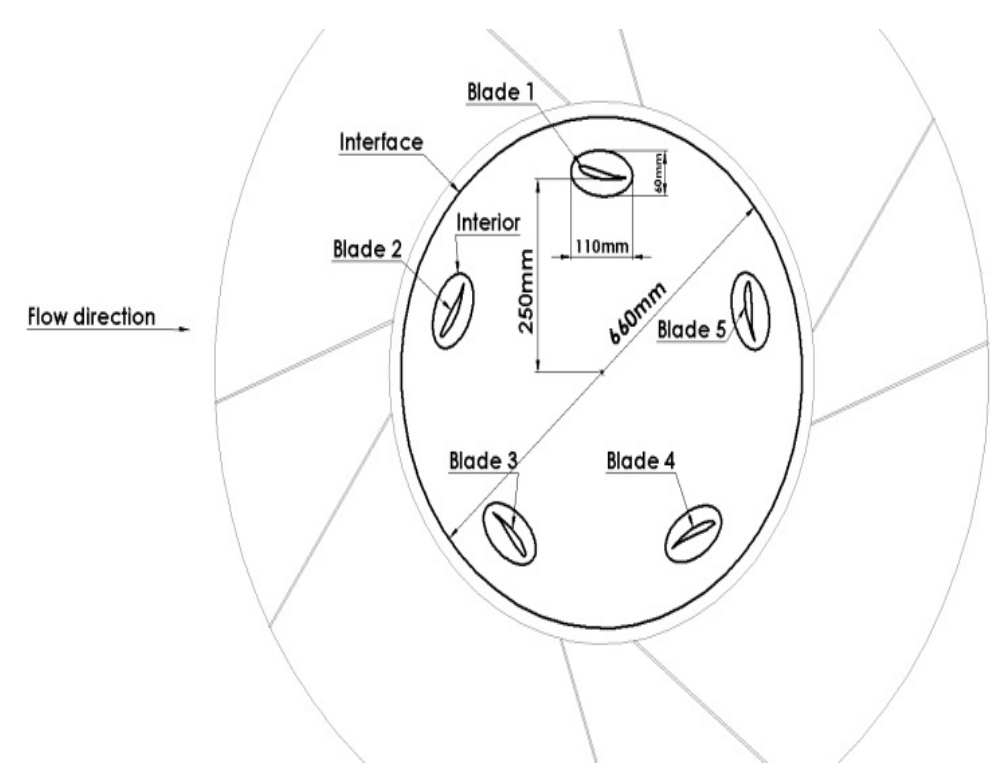

Figure 5. Boundary around the VAWT.

As can be seen from Figure 5, the moving mesh approach has been employed to show the rotation zone and an interface boundary is created between the rotating and non-rotating sections. The same mesh density is selected for both sides of the interface to obtain faster convergence [32]. The initial position of the blades is also shown in Figure 5. Blade 1 starts from $\theta=0^{\circ}$ while the initial position of the blades number $2,3,4,5$ is $\theta=72^{\circ}, 144^{\circ}, 216^{\circ}, 288^{\circ}$ respectively. Considering the complexity of the geometry, unstructured mesh is chosen. The first and second size functions have been employed to generate mesh from blades and control elapse to the rotor interface respectively. The third functions have been used to generate mesh for the wind tunnel domain and the fourth size function produce mesh on the ODGV. These four functions have been defined in Table 2. 
Table 2. Mesh properties.

\begin{tabular}{|c|c|c|c|c|c|c|c|c|c|}
\hline Mesh & $\begin{array}{c}\text { Ratio } \\
\text { Start Size } \\
\text { End Size }\end{array}$ & $\begin{array}{c}\text { Size } \\
\text { Function } 1\end{array}$ & $\begin{array}{c}\text { Size } \\
\text { Function } 2\end{array}$ & $\begin{array}{c}\text { Size } \\
\text { Function } 3\end{array}$ & $\begin{array}{c}\text { Size } \\
\text { Function } 4\end{array}$ & $\begin{array}{l}\text { Mesh Sizeon } \\
\text { Airfoil (mm) }\end{array}$ & $\begin{array}{l}\text { Number of Nodes } \\
\text { on Airfoil Surface }\end{array}$ & $\begin{array}{c}\text { Simulation } \\
\text { Average Time (h) }\end{array}$ & $\begin{array}{l}\text { Number of } \\
\text { Total Cells }\end{array}$ \\
\hline \multirow{3}{*}{ M1 } & Ratio & 1.1 & 1.1 & 1.1 & 1 & \multirow{3}{*}{0.3} & \multirow{3}{*}{532} & \multirow{3}{*}{1} & \multirow{3}{*}{150,000} \\
\hline & Start Size & 0.3 & 0.5 & 5 & 5 & & & & \\
\hline & End size & 0.5 & 5 & 200 & 5 & & & & \\
\hline \multirow{3}{*}{ M2 } & Ratio & 1.05 & 1.05 & 1.05 & 1.1 & \multirow{3}{*}{0.25} & \multirow{3}{*}{638} & \multirow{3}{*}{4} & \multirow{3}{*}{255,000} \\
\hline & Start Size & 0.25 & 0.5 & 5 & 3 & & & & \\
\hline & End size & 0.5 & 3 & 200 & 5 & & & & \\
\hline \multirow{3}{*}{ M3 } & Ratio & 1.05 & 1.05 & 1.05 & 1.1 & \multirow{3}{*}{0.2} & \multirow{3}{*}{798} & \multirow{3}{*}{8} & \multirow{3}{*}{350,000} \\
\hline & Start Size & 0.2 & 0.5 & 5 & 3 & & & & \\
\hline & End size & 0.5 & 3 & 200 & 5 & & & & \\
\hline \multirow{3}{*}{ M4 } & Ratio & 1.05 & 1.05 & 1.05 & 1.1 & \multirow{3}{*}{0.1} & \multirow{3}{*}{1595} & \multirow{3}{*}{12} & \multirow{3}{*}{840,000} \\
\hline & Start Size & 0.1 & 0.5 & 5 & 2 & & & & \\
\hline & End size & 0.5 & 2 & 200 & 5 & & & & \\
\hline \multirow{3}{*}{ M5 } & Ratio & 1.05 & 1.05 & 1.05 & 1.1 & \multirow{3}{*}{0.0} & \multirow{3}{*}{3190} & \multirow{3}{*}{26} & \multirow{3}{*}{$1,500,000$} \\
\hline & Start Size & 0.05 & 0.5 & 5 & 2 & & & & \\
\hline & End size & 0.5 & 2 & 200 & 5 & & & & \\
\hline
\end{tabular}


The generation of mesh starts from the airfoils; $0.1 \mathrm{~mm}$ was considered as the optimum size of mesh around the airfoil after the mesh independency test. The mesh was expanded with the first size function with a ratio of 1.05 from $0.1 \mathrm{~mm}$ to $0.5 \mathrm{~mm}$, which is indicated by Figure 6 .

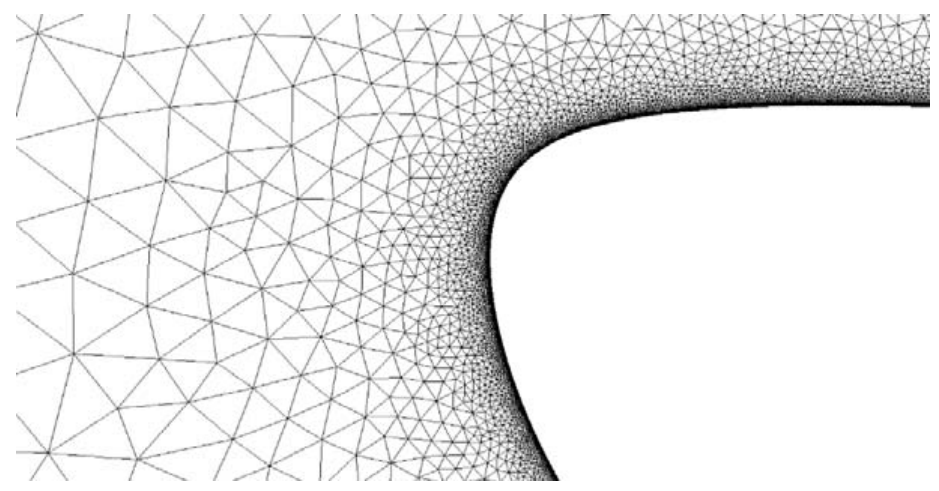

Figure 6. Density of the mesh near the blade.

In order to accurate capture the flow behavior and obtain a suitable $Y_{\text {plus }}$ range around the blades, ten boundary layers of the structural mesh are generated and illustrated in Figure 7.

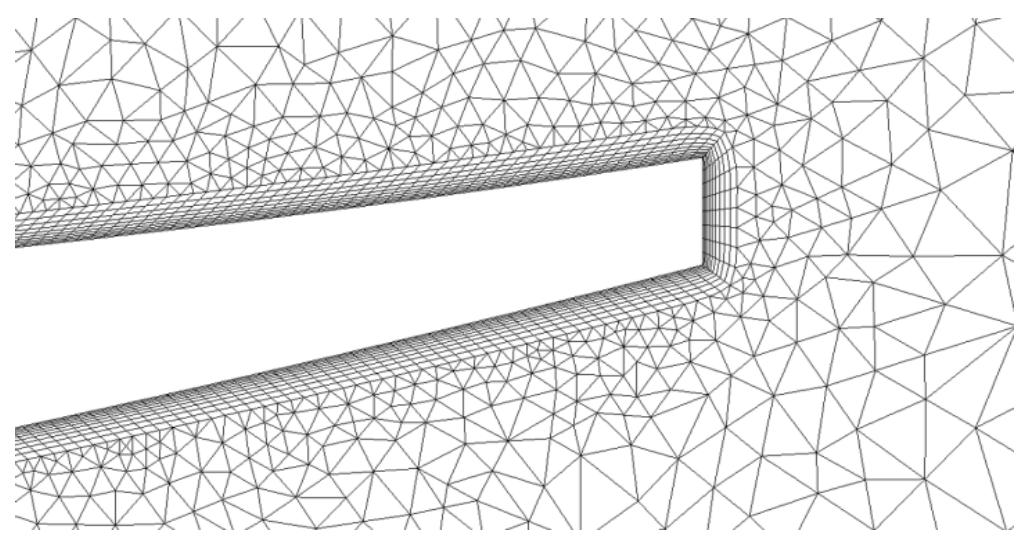

Figure 7. Boundary layers mesh around blade.

In order to control the grid elements dimension near the blades, blades are enclosed in a control ellipse which is shown by Figure 8 .

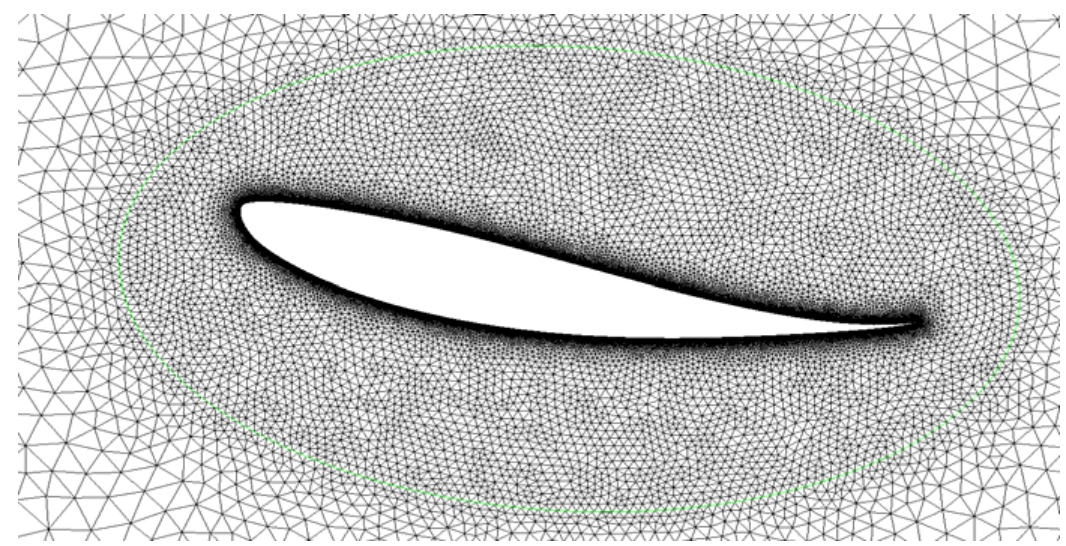

Figure 8. Control ellipse. 
Control ellipses unlike the interface, has no physical significance. The second size function with a ratio of 1.05, generates the mesh from control ellipse with mesh size of $0.5 \mathrm{~mm}$ to the rotational zone with mesh size of the $2 \mathrm{~mm}$. last size function creates a mesh from the interface to the wind tunnel domain with a ratio of 1.05. Mesh was expanded from $2 \mathrm{~mm}$ to $200 \mathrm{~mm}$ in the wind turbine domain. After that with regards to the ODGV geometry, another size function has been used to cover the gap between ODGV and the interface with a ratio of 1.1 from $2 \mathrm{~mm}$ to $5 \mathrm{~mm}$. In addition, the size of ODGV mesh in all cases is $5 \mathrm{~mm}$.

Two symmetrical boundary conditions have been used for two side walls. To ensure the continuity of the flow field, the circumference around the turbine rotational axis was set as an interface, which is shown in Figure 5. Testing domain was divided in to the two different zones by means of the interface around turbine. The rotational part of the VAWT and non-rotational part of the wind tunnel (including the ODGV and wind tunnel), were defined as the inner and outer zones, respectively. Between these two zones, the interface boundary is created to ensure the mesh connection between the rotational and wind tunnel zone.

On the other hand, one important criterion in every CFD simulation is the wall $Y_{\text {plus }}$. It is important in turbulence modeling to determine the proper size of the cells near domain walls. The turbulence model wall laws have restrictions on the $Y_{\text {plus }}$ value at the wall. This dimensionless wall distance depends on the first cell height. In this study, $Y_{\text {plus }}$ values have been measured for the various positions of one airfoil between 0 and 1 for 5 different Azimuth angles including $0^{\circ}, 72^{\circ}, 144^{\circ}, 216^{\circ}$ and $288^{\circ}$ in $T S R=3$. Figure 9 shows the result of the average value.

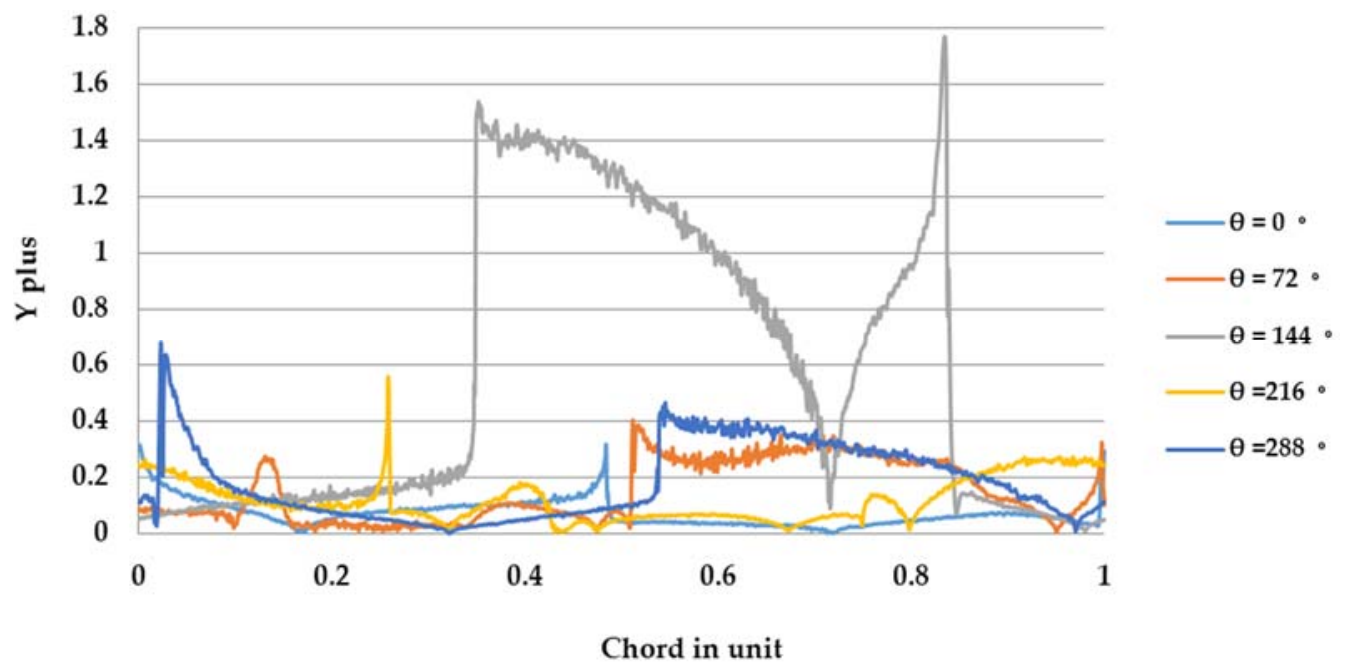

Figure 9. Results for $Y_{p l u s}$ values when the $T S R=3$.

As it can be seen from Figure 9, the maximum value for $Y_{\text {plus }}$ is reported for $\theta=144^{\circ}$ at a range of 1.8. For the rest of the airfoil positions the $Y_{\text {plus }}$ range is less than 0.7 as can be observed.

\subsection{The Flow Solver and Turbulence Model}

The educational version of ANSYS FLUENT15 was employed to perform the CFD study on the aerodynamics of the VAWT. The numerical solver which has been used in this software, is based on the solving RANS equations and the finite-volume method. A main challenge in most of the CFD code is selection of the right turbulence model, which is highly dependent on the nature of the considered flow. Its mathematical nature can affect the computational resources, time and result accuracy. Wang et al. [35] have showed that Large Eddy Simulation (LES) and the RANS are the most common modelling approaches in the CFD simulations. Typically, the LES is appropriate for the 3-D simulations, while RANS method is suitable for 2-D numerical study. Three different RANS turbulence 
models are analyzed, namely the standard $k-\omega$, the standard $k-\varepsilon$ and, the $k-\omega$ Shear Stress Transport (SST) model. These three turbulence models are classified as two-equation turbulence models, as they include two extra transport equations to represent the turbulent properties of the flow. One variable determines the energy in the turbulence, while the other variable considers the scale of the turbulence.

\subsection{Mesh Dependency Study}

The full 2-D model of a vertical axis wind turbine have been widely analysed by a large number of researchers who achieved a mesh independent solution before considering the full 3-D model. McLaren et al. [36] carried out a mesh independency study with 989 elements on each airfoil and a total mesh count of 485,000 nodes. A systematic refinement of the mesh from 600,000 to 1,000,000 cells was performed by Castelli [37] to obtain a mesh independent solution. It is important to highlight that coarse meshes in range of 100,000 to 300,000 cells, were employed by some researchers such as [38-41]. In these cases, a non-transitional model was applied for the airfoil when number of the cells on surface is fixed. Although this model resulted in a smooth solution, it is not required to have a mesh independent solution. Therefore, a further mesh independency analysis was required in this situation. A more detailed mesh independency study was performed by Maître et al. [42] who systematically employed seven various cases. However, six of these cases were exactly have the same number of cells on the blades which means that this mesh independent solution was not accurate.

The accuracy of the CFD simulation is highly dependent on the quality of the mesh. To determine this effect, large number of simulations have been carried out in this studies. Table 2 shows mesh properties in different situations.

Torque and power coefficients $\left(C_{P}\right.$ and $\left.C_{Q}\right)$ of the VAWT were tested by using five different types of mesh when the TSR is 0.654 , with wind speed $U_{\infty}=6 \mathrm{~m} / \mathrm{s}$. Figure 10 shows the $C_{Q}$ generation versus the azimuth angle at TSR $=0.654$ in different types of meshes.

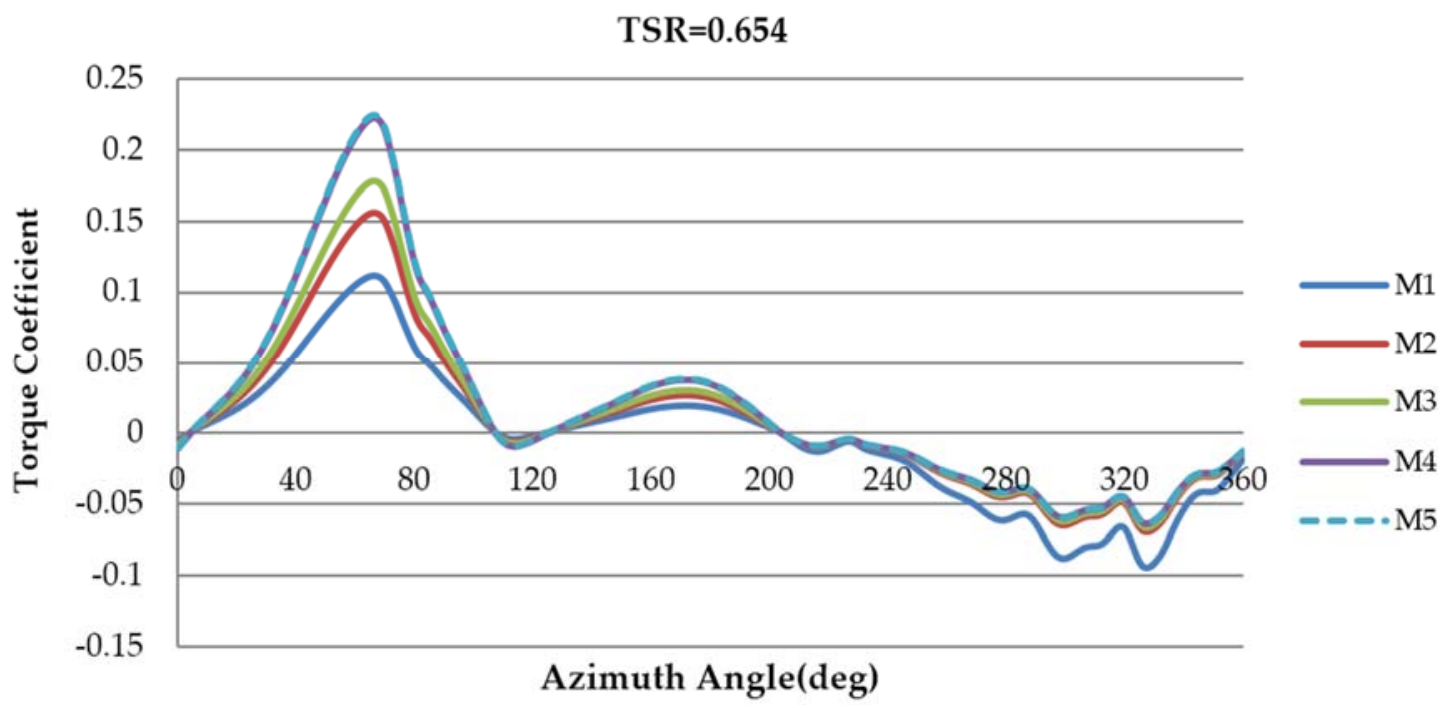

Figure 10. Mesh dependency test in $T S R=0.654$.

As can be seen from Figure 10, M4 and M5 have almost same results for initial azimuth positions $\theta=0^{\circ}$ and $\theta=100^{\circ}$. However, increasing the number of cells leads to a significant difference in the $C_{Q}$ between M1 and M3. It can clearly be observed that the maximum generation of energy is at $\theta=65^{\circ}$ and the negative value for $C_{Q}$ is reported for all cases when the blade is between $\theta=200^{\circ}$ and $\theta=360^{\circ}$. Figure 11 shows the variation of the power coefficient for different types of mesh in $T S R=0.654$. 


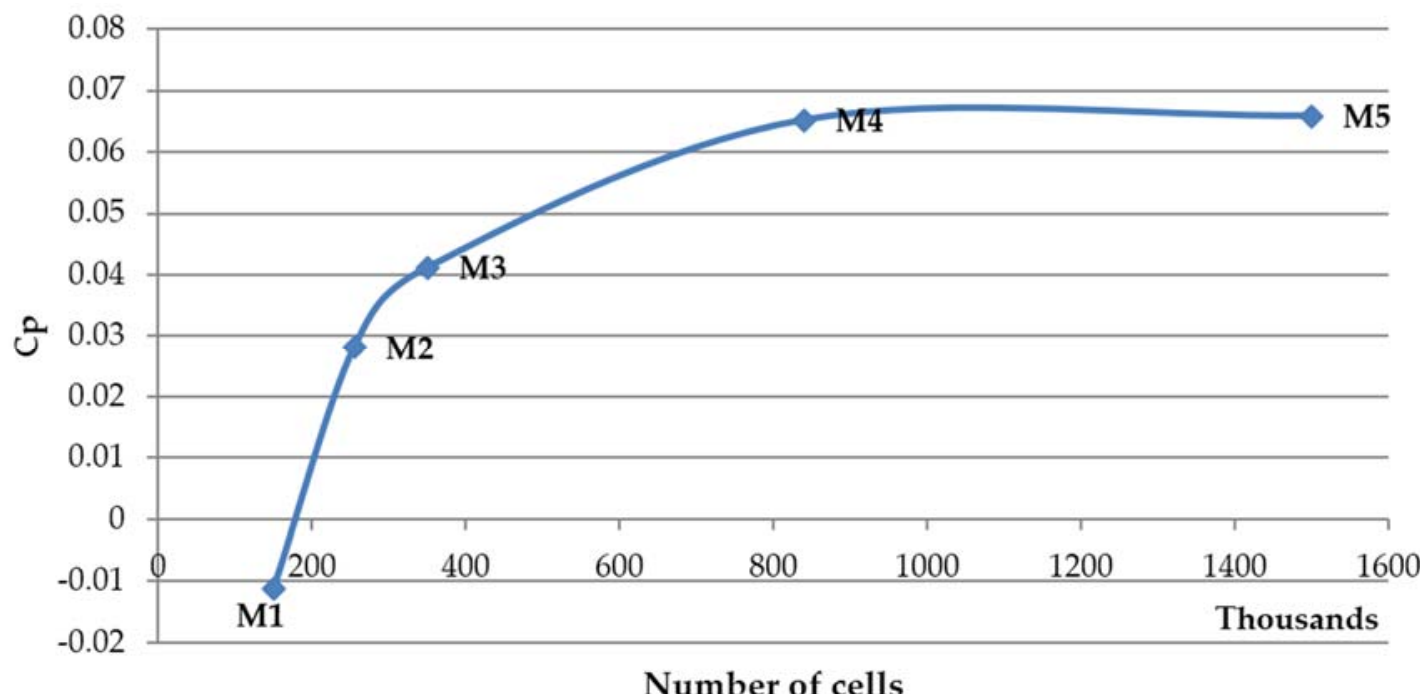

Figure 11. Variation of the $C_{P}$ in different types of mesh in $T S R=0.654$.

In addition, Figure 11 shows M4 and M5 generate maximum $C_{P}$ and also the difference of the $C_{P}$ is small in these two meshes. Therefore, the M4 results show the most appropriate results.

\subsection{Time Dependency Study}

Based on a previous research by Qin et al. [43], the convergence of the CFD simulation depends on choosing the right time step $(d t)$. Therefore, three different time steps based on the rotational speed of the VAWT, have been examined to achieve a good and reliable result. The largest time step is equal to $2^{\circ} \omega^{-1}$ (the time equivalent to two degrees of one revolution) which is equal to 180 steps per one rotation. While the second time step is half of the first one $\left(d t=1^{\circ} \omega^{-1}\right.$ which means 360 step per one rotation), and the third one is ( $d t=0.5^{\circ} \omega^{-1}$ which represents 720 step per one rotation), when the TSR is 0.654 . Figure 11 shows the time dependency which has been employed in this study. As shown in Figure 12, there is a very small difference in the results of the $C_{Q}$ in case of $d t=1^{\circ} \omega^{-1}$ and $0.5^{\circ} \omega^{-1}$. Hence, $d t=1^{\circ} \omega^{-1}$ is selected for the successive numerical simulations in order to reduce the computational time to minimum.

TSR $=0.654$

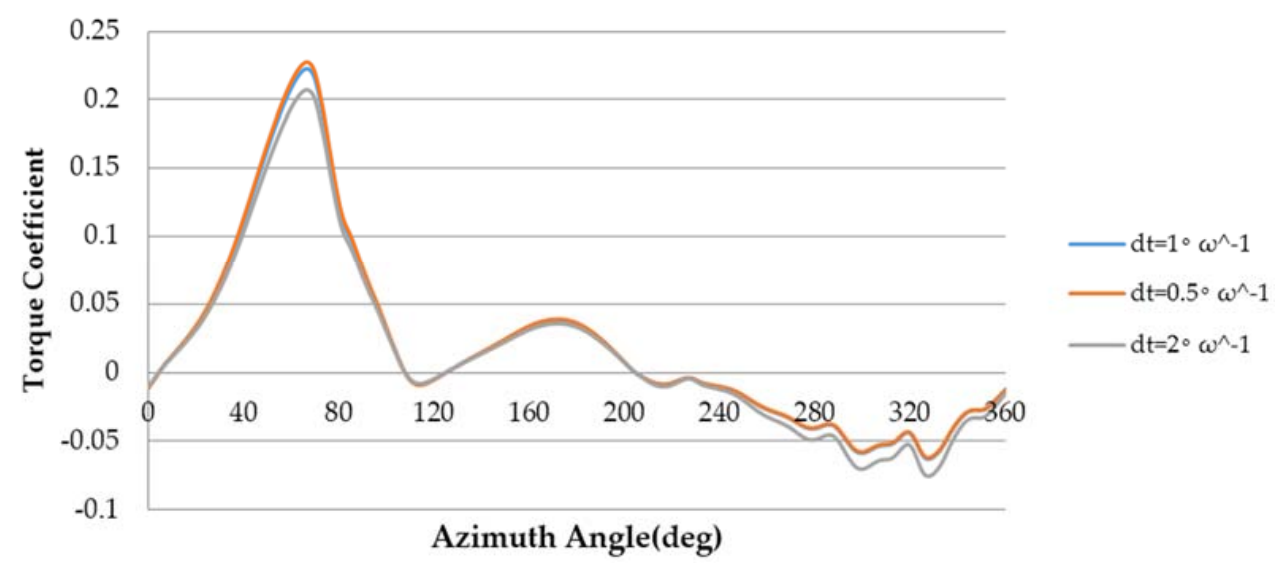

Figure 12. Time dependency study.

\subsection{Turbulence Model Study}

In order to choose the best turbulence model, three different RANS turbulence models were investigated; namely, Standard $k-\varepsilon$, Standard $k-\omega$ and transition SST. All simulations in this part have 
been done with the time step equals to $1^{\circ} \omega^{-1}$ at TSR of 0.654 . Figure 13 shows the obtained torque coefficient of VAWT using different turbulence models.

$\mathrm{TSR}=\mathbf{0 . 6 5 4}$

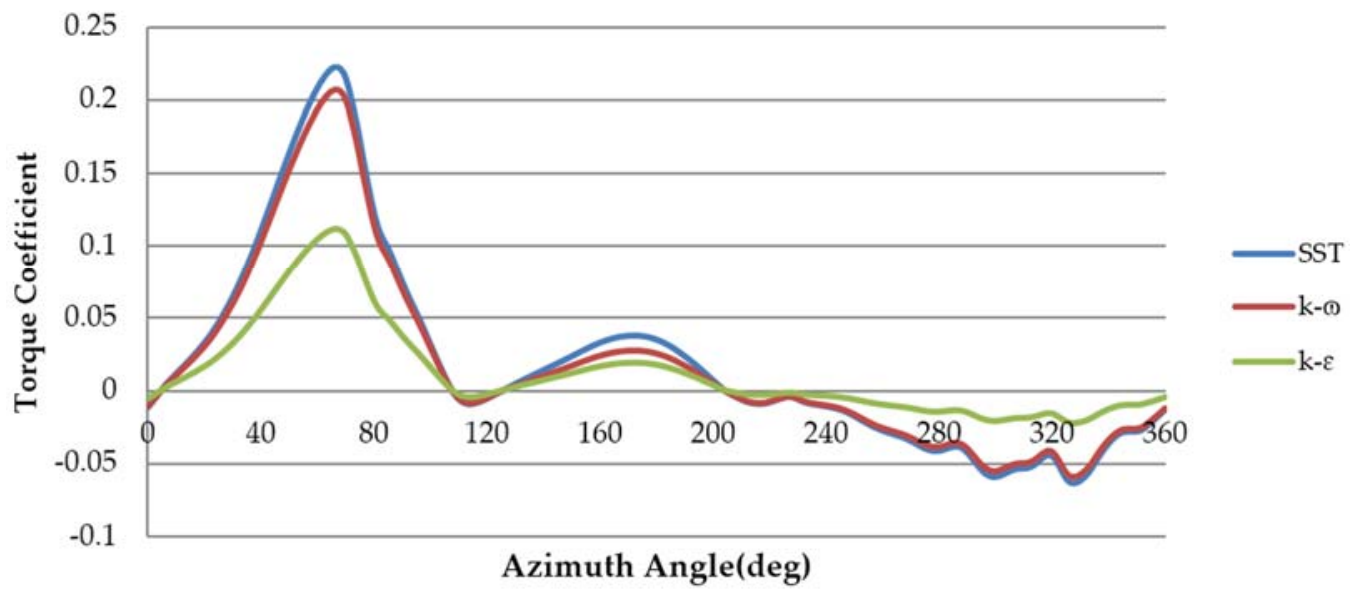

Figure 13. Turbulence models for VAWT simulation.

As it is manifested, there are very small dissimilarities in the downstream flow between the Standard $k-\omega$ and the transition SST, and same results can be observed in the upstream area for both models. The standard $k-\varepsilon$ models do not provide good results for the upstream flow when comparing to the standard $k-\omega$ and transition SST models. A similar outcome has been obtained in other related literature, such as $[6,9,13,44]$. Considering the results of the simulations in different turbulence models, transitional k- $\omega$ SST model was chosen as a proper turbulence model for the rest of the simulations.

\subsection{CFD Validation}

The numerical study has been validated by the experimental data to verify the accuracy of the CFD results. For this purpose, a wind tunnel testing was conducted at the Aeronautics Laboratory in University Technology Malaysia. Figure 14 indicates configuration of the testing unit in this wind tunnel. As shown in Figure 15, wind tunnel testing was conducted for a turbine consisting of five blades with a section profile of FX63-137. For this test, the blade chord length was designed as $78 \mathrm{~mm}$ in a H-rotor wind turbine with $500 \mathrm{~mm}$ rotor diameter and a height of $350 \mathrm{~mm}$.

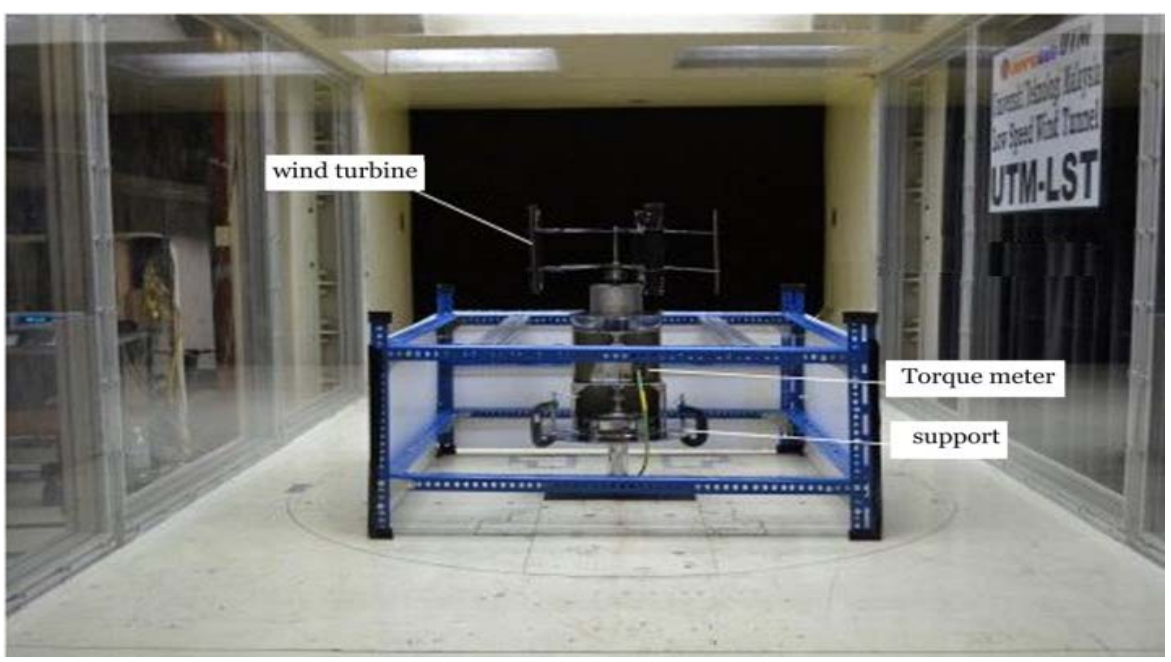

Figure 14. Configuration of the testing unit in wind tunnel. 
An identical wind speed, i.e., $6 \mathrm{~m} / \mathrm{s}$, was used in the following experiment to compare the rotational speed (RPM) and power generated by the wind turbine. The rotational speed, torque and power generation were measured via a transducer, which is connected in-line with the rotor shaft of the wind turbine. The load is applied on the rotor shaft by adjusting the hysteresis brake. The maximum torque experienced by the rotor at the particular wind speed was recorded when the highest load had been applied on the rotor which RPM is stabilized (the rotor RPM can be maintained). Two types of bearings were employed in the rotor shaft connection and fitting including. A tapered roller bearing and a deep groove ball one. The experimental results of wind tunnel testing has been compared with CFD simulation results and shown as below (Figure 15):

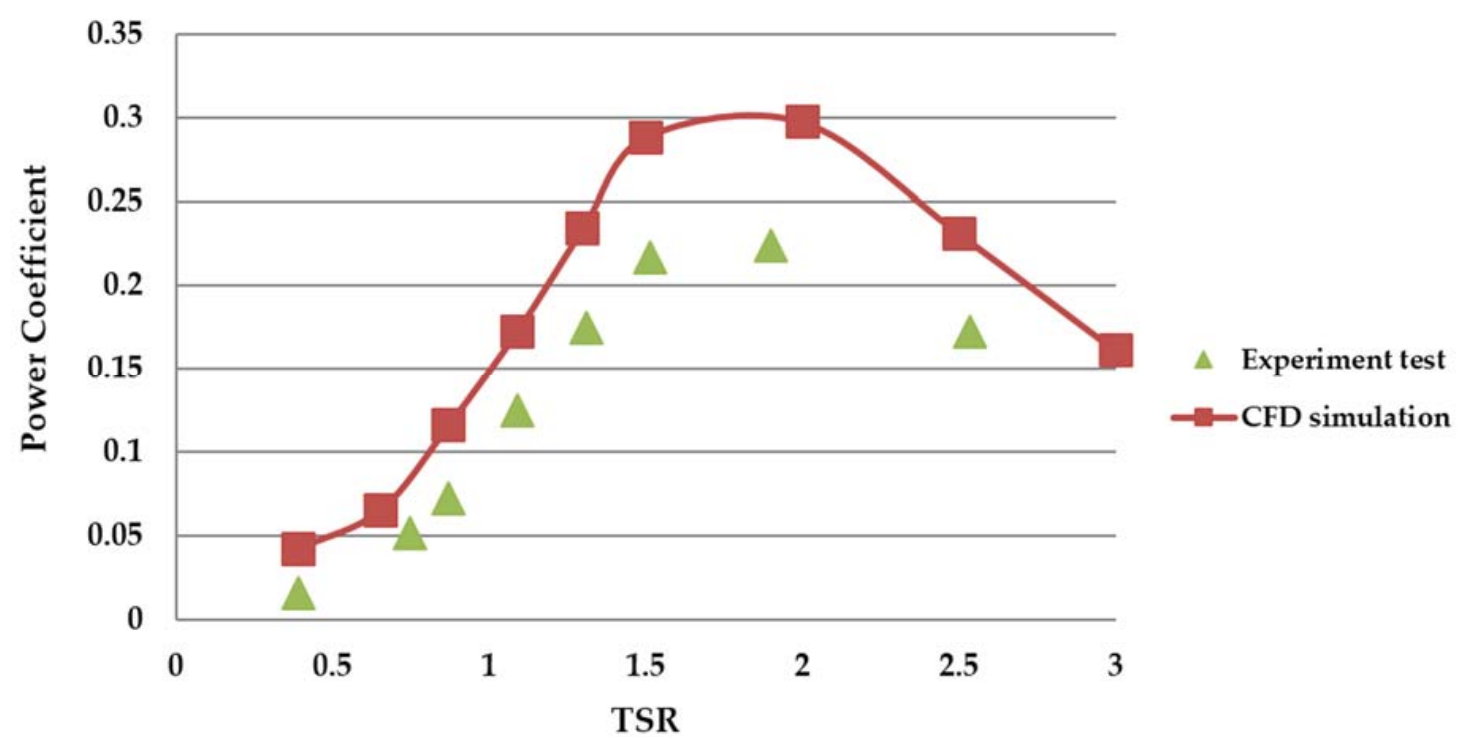

Figure 15. Results of the coefficient of the power in wind tunnel experimental test data compared to the CFD simulation.

Figure 15 shows the differences between the CFD simulation and the experimental data of the open rotor VAWT. Based on this figure, a similar trend can be observed between the CFD simulation and the experimental results and they are in good agreement.

This trend and differences have been also observed by previous studies. Nobile et al. [13] and Castelli et al. [37] reported almost the same differences between CFD and the experimental data. They mentioned that this dissimilarity could be related to the tip vertices effect, blade length and spoke drag which are not considered in a 2-D simulation. Furthermore, in this study the effect of two supporting arms and central shaft was neglected. Therefore these assumptions are bound to create some differences in the prediction of the CFD results and to the actual experimental ones.

\section{Results}

\subsection{Case 1: Open Rotor}

In this section, the numerical results of the different cases are analyzed and some simulations are performed at TSR between 0.393 and 3, to observe the variation of turbine performance based on rotational speed. For visualization of the flow field, the magnitude of the velocity contours and power coefficient graph are also plotted. In addition, the oscillation of the $C_{Q}$ in one rotation for all five individual blades accompanied by their total at $T S R=0.654$, is illustrated by Figure 16 . 
$\mathrm{TSR}=0.654$

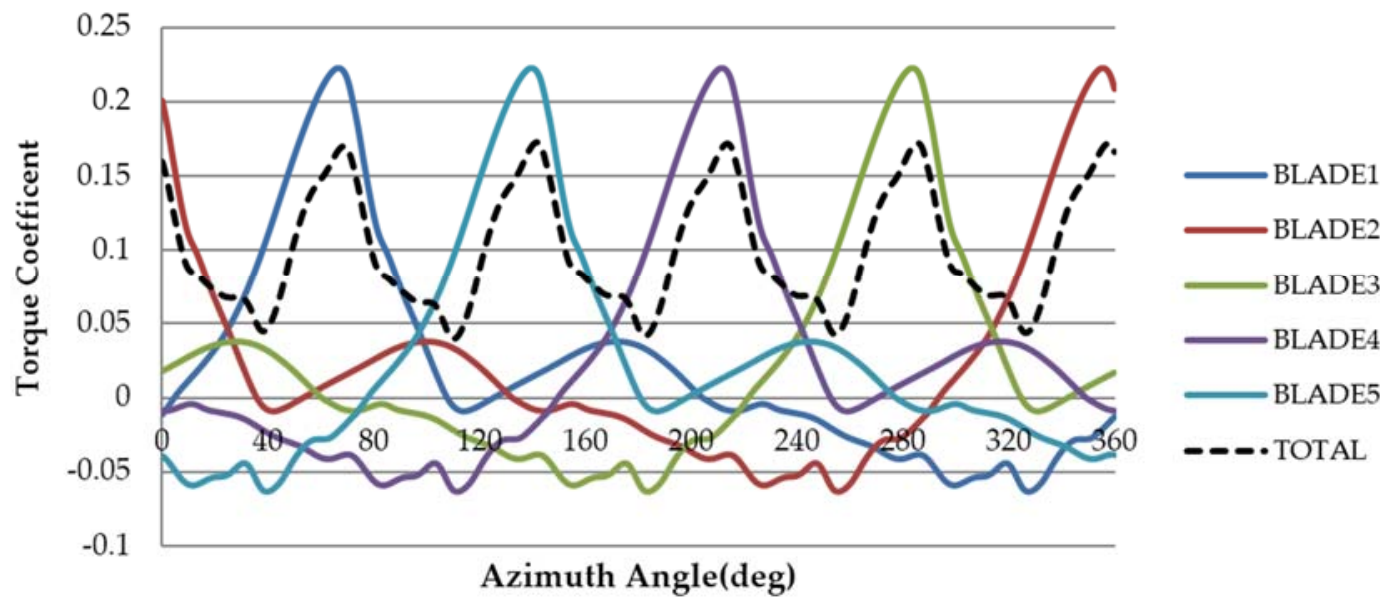

Figure 16. Predicted torque coefficient for five individual blades.

It can be seen that the maximum torque for the first blade has been achieved at the azimuth angle of $\theta=60^{\circ}$. After the peak, the drag begins to increase as the blade enters into a dynamic stall, and the drag starts to be dominant until the azimuth angle of $\theta=110^{\circ}$. Again a positive torque was reported between the azimuth angle of $\theta=110^{\circ}$ and $\theta=200^{\circ}$. After $\theta=200^{\circ}$ a negative torque was generated by the blade and the drag force is again dominant until $\theta=5^{\circ}$. The overall torque generation for the five blades in the open rotor case is reported by dashed lines in Figure 16. As well, Figure 17 shows the variation of the $C_{Q}$ on a single blade at different tip speed ratios during one rotation.

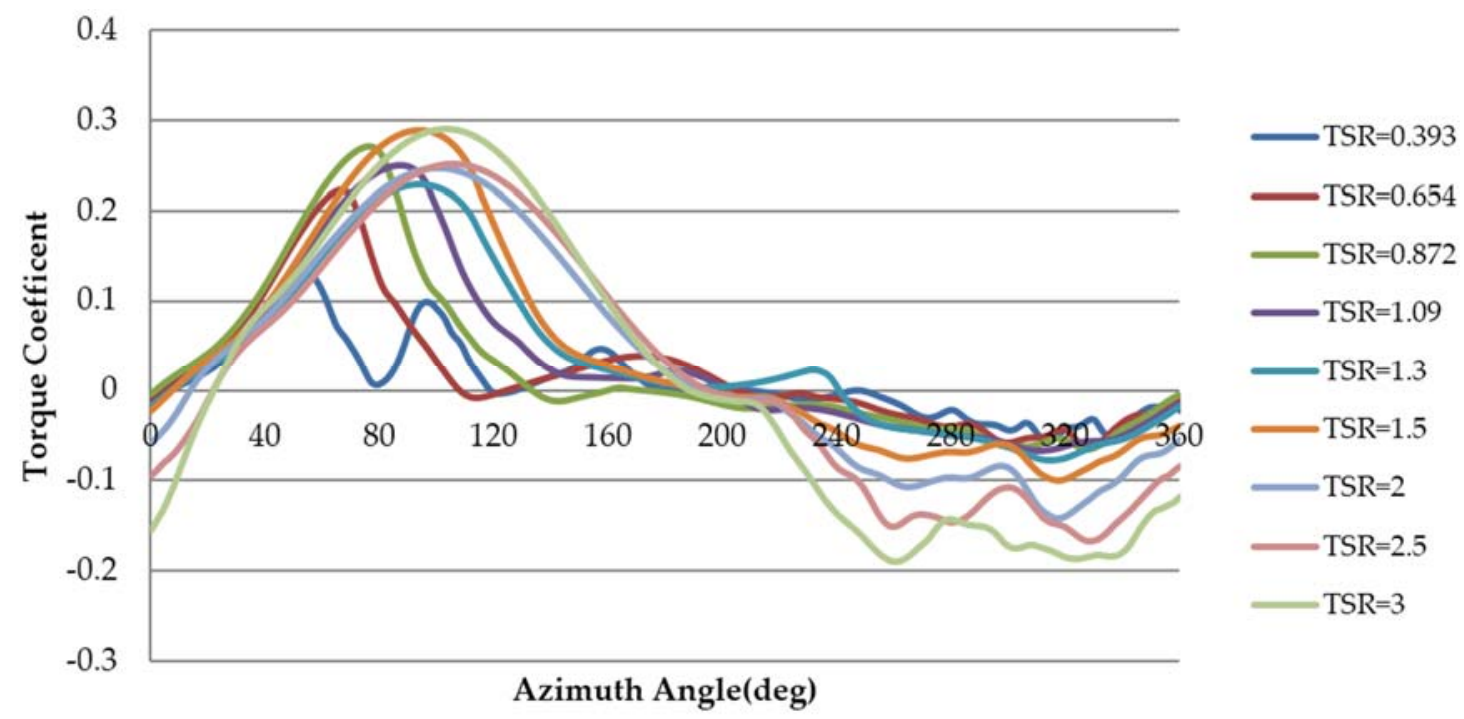

Figure 17. Torque coefficient variation in different TSR.

These results have been achieved from the simulation of the open rotor (only VAWT) without using ODGV when the wind speed is as much as $6 \mathrm{~m} / \mathrm{s}$. It is apparent from Figure 17 that by increasing the tip speed ratio, $C_{Q}$ shows a different behavior. After the azimuth angle of $\theta=200^{\circ}$, in almost all TSRs, a negative $C_{Q}$ can be observed. The maximum negative $C_{Q}$ is achieved in TSR $=3$.

On the other hand, the unsteady flow field is expected to be complex, particularly due to the wake effect. This effect can be seen from the velocity contour in Figure 18. 


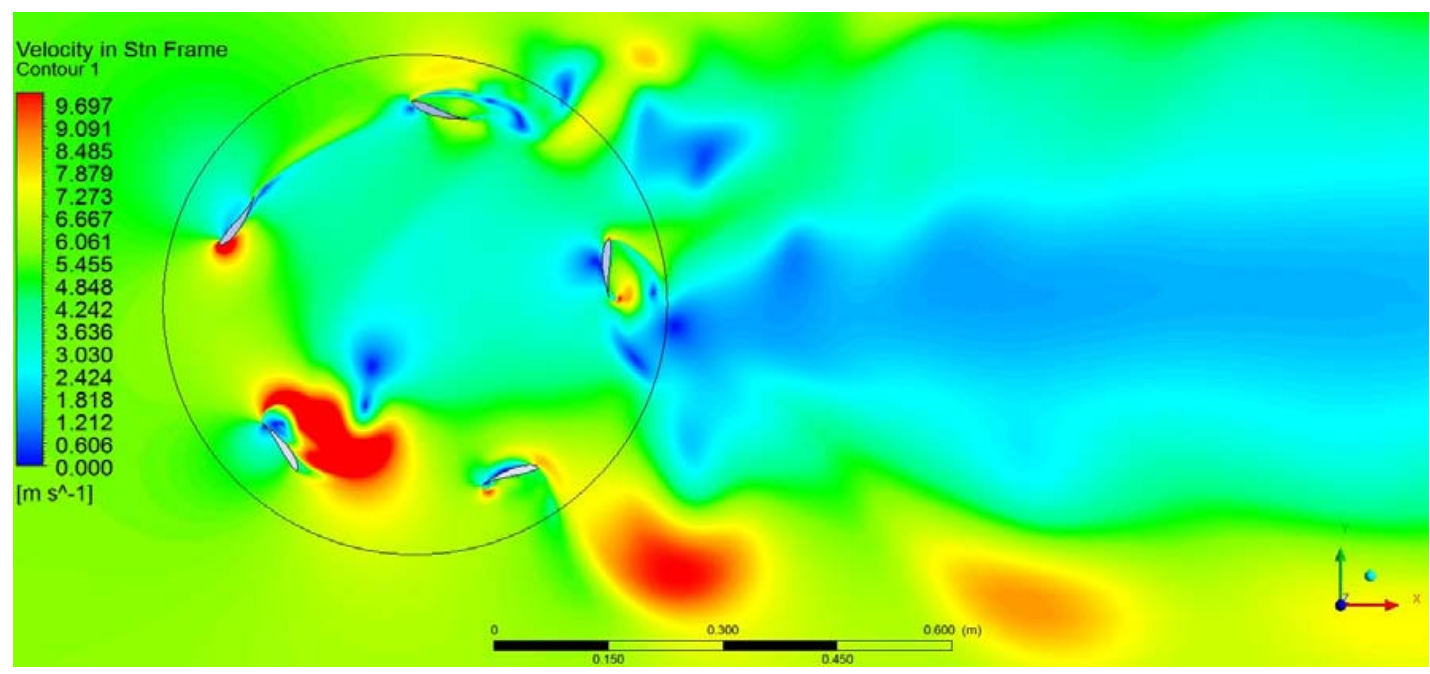

Figure 18. Contour of velocity magnitude for open rotor.

As can be seen from Figure 18, the wake from the leading blade interacts with the following blades and velocity can reach to velocities even more than $9(\mathrm{~m} / \mathrm{s})$. In order to perceive the effect of TSR on turbine performance, the average torque coefficients achieved in different TSRs are depicted in Figure 19.

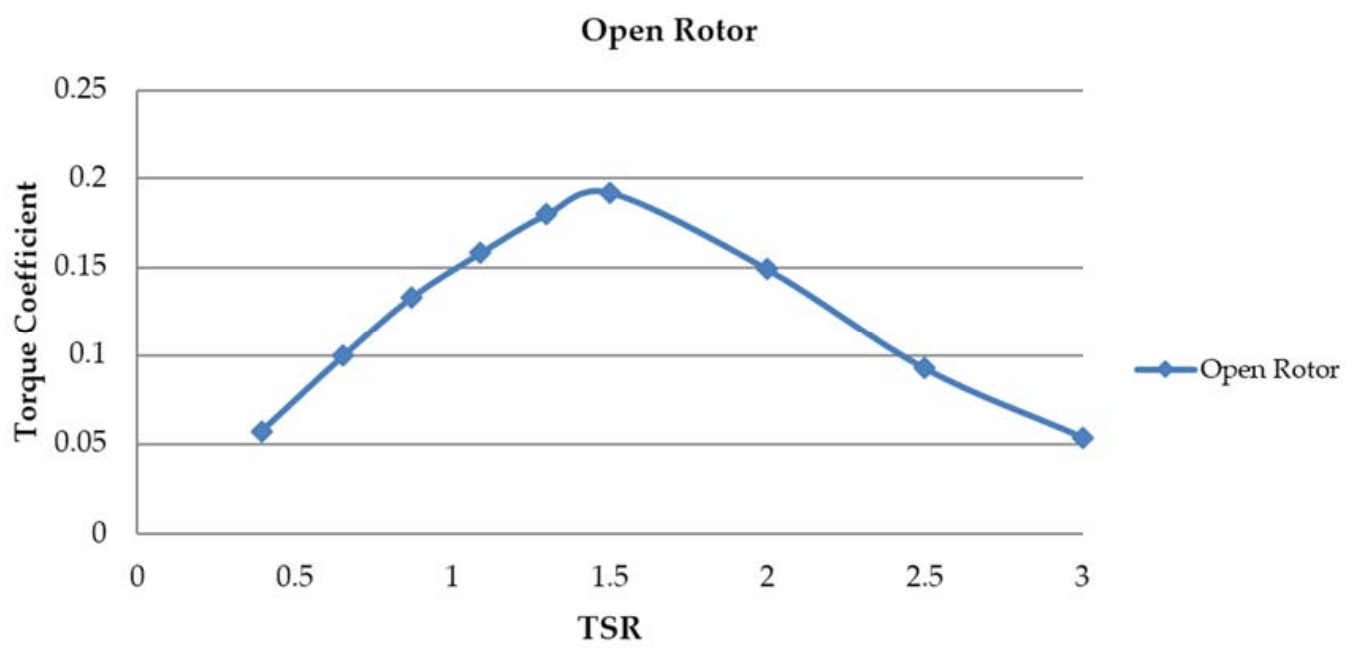

Figure 19. Average $C_{Q}$ for different TSRs.

According to this figure, TSR and $C_{Q}$ are in a direct relationship when the TSR is between 0.393 and 1.5. However, TSR and $C_{Q}$ trends are oposite when for TSRs are greater than 1.5. The maximum value of the $C_{Q}$ has been achieved when TSR is 1.5 .

\subsection{Case 2: Augmented Rotor and Open Rotor}

In Case 2, the power output of an augmented rotor has been compared with an open rotor and effect of ODGV on the VAWT is investigated for a constant shape ratio. In this case, the shape ratio for the ODGV was fixed at 0.55, the outer diameter of the ODGV was $1272 \mathrm{~mm}$ and nine different TSRs for both the open rotor and the augmented rotor have been tested to assess the influence of ODGV on VAWT performances. On the other hand, like most numerical iteration methods, a suitable convergence criterion is required for accurate simulation results. Indeed, the results are completely changed by changing the convergence criterion. The convergence criterion is a general concept which 
cannot be obtained precisely when the model is non-linear model and it is typically employed to eradicate non-linearity in the numerical solution. Typically, it has been chosen between $10^{-3}$ and $10^{-5}$, in this study the criterion is selected as a minimum error. In this study, the convergence criterion is selected $10^{-5}$ as a reseonable amount. Figure 20 shows a variation of the $C_{Q}$ versus azimuth angle for the open and augmented rotor.

$\mathrm{TSR}=0.654, \mathrm{R}=0.55$

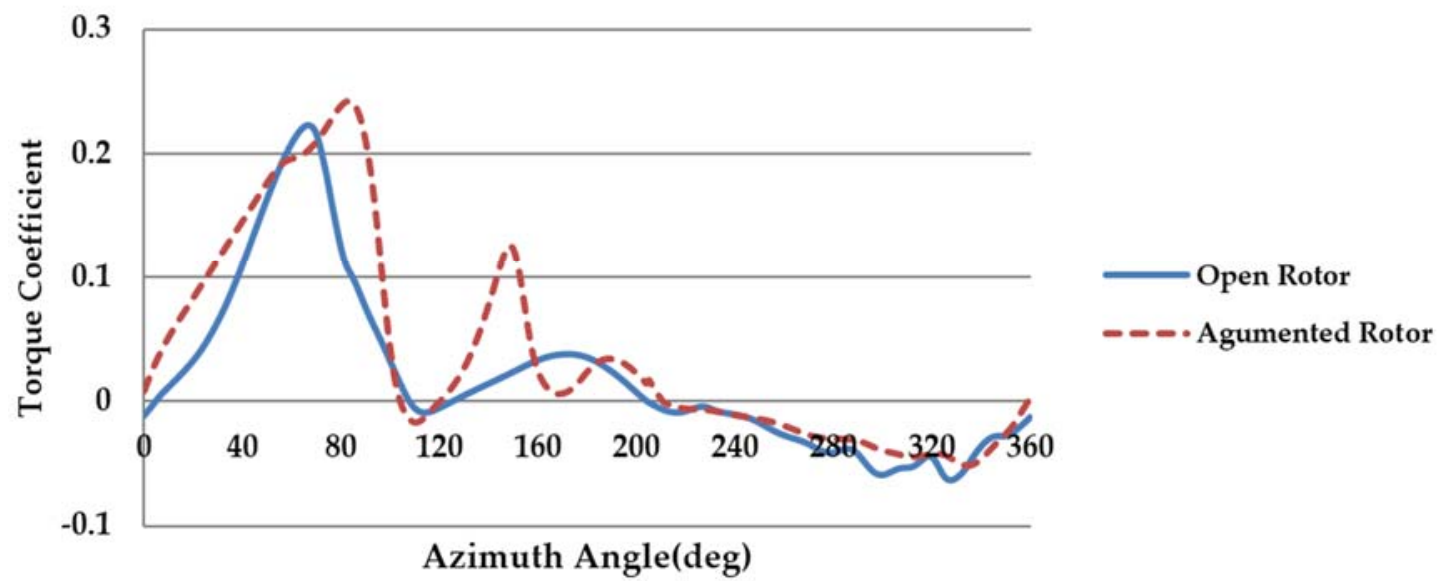

Figure 20. Torque coefficient versus azimuth angle for open and augmented rotor for TSR $=0.654$, $R_{\text {shape-ratio }}=0.55$.

The dashed line in Figure 20 shows the augmented rotor while the solid line indicates only the VAWT without using ODGV. The results are achieved for TSR $=0.654$ for both the open and augmented rotor. Regarding the turbulence model as discussed in the previous section, SST Transient was selected and $d t=1^{\circ} \omega^{-1}$ was set for the time step during the simulation. Clearly, it can be seen from the results that the torque coefficients of the rotor have been significantly improved by using OGDV. This effect is mostly apparent when the azimuth angle is between $0^{\circ}$ and $160^{\circ}$. Three general peaks were reported in the augmented rotor. The maximum $C_{Q}$ for the augmented rotor is achieved when the azimuth angle is $85^{\circ}$ while for the open rotor it is $60^{\circ}$. The second peak of the augmented rotor is at $\theta=150^{\circ}$ and the last one is at $\theta=190^{\circ}$. In addition, using ODGV has decreased the amount of the negative torque generation after the azimuth angle of $200^{\circ}$. The same simulations have also been conducted at 4 different other TSRs including 1, 1.5, 2 and 3. The results of these simulations are illustrated by Figures 21-24.

TSR=1, R=0.55

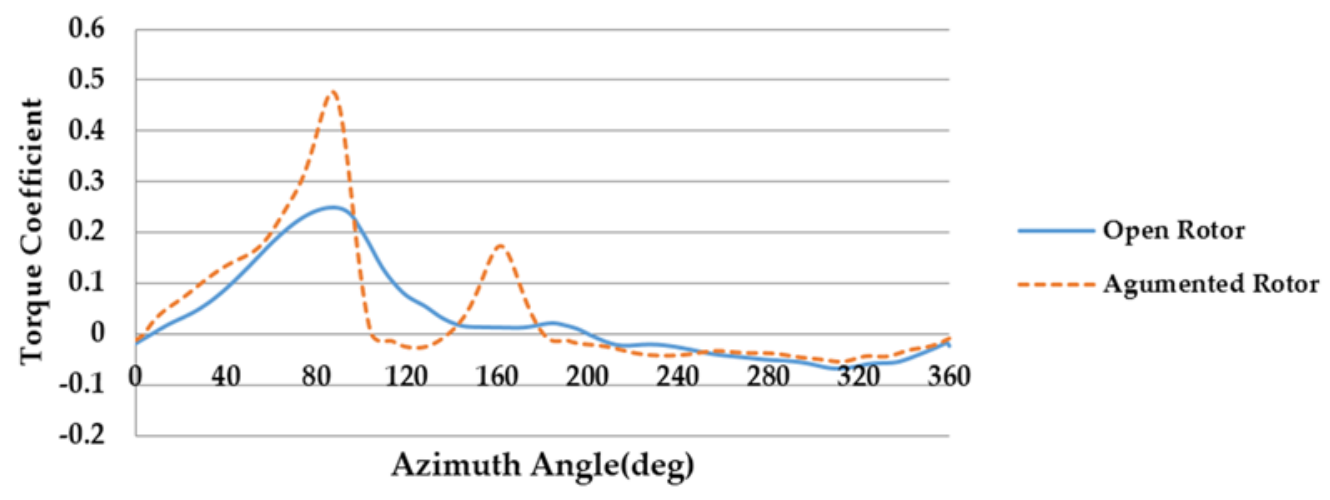

Figure 21. Torque coefficient versus azimuth angle for open and augmented rotor for $T S R=1$, $R_{\text {shape-ratio }}=0.55$. 
TSR=1.5, R=0.55

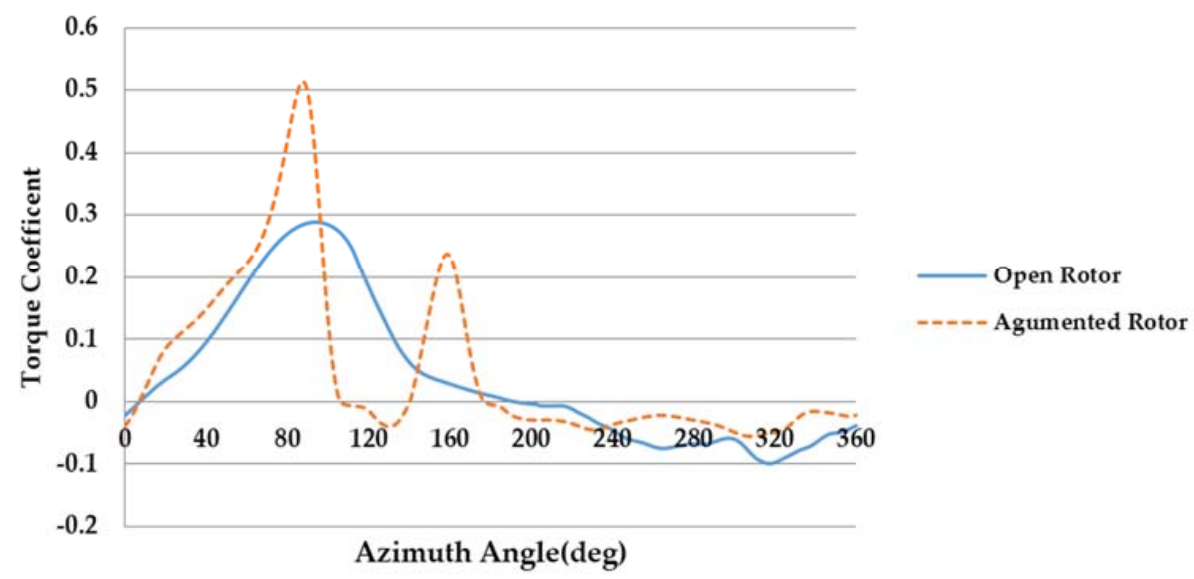

Figure 22. Torque coefficient versus azimuth angle for open and augmented rotor for TSR $=1.5$, $R_{\text {shape-ratio }}=0.55$.

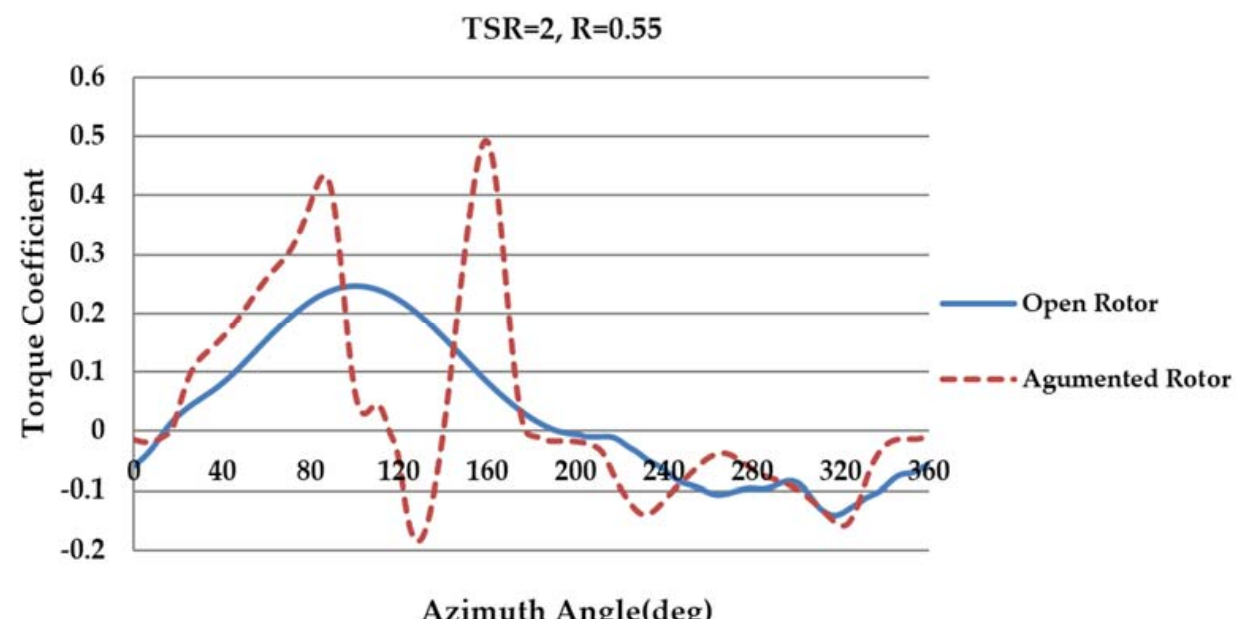

Figure 23. Torque coefficient versus azimuth angle for open and augmented rotor for $\operatorname{TSR}=2$, $R_{\text {shape-ratio }}=0.55$.

$\mathrm{TSR}=3, \mathrm{R}=0.55$

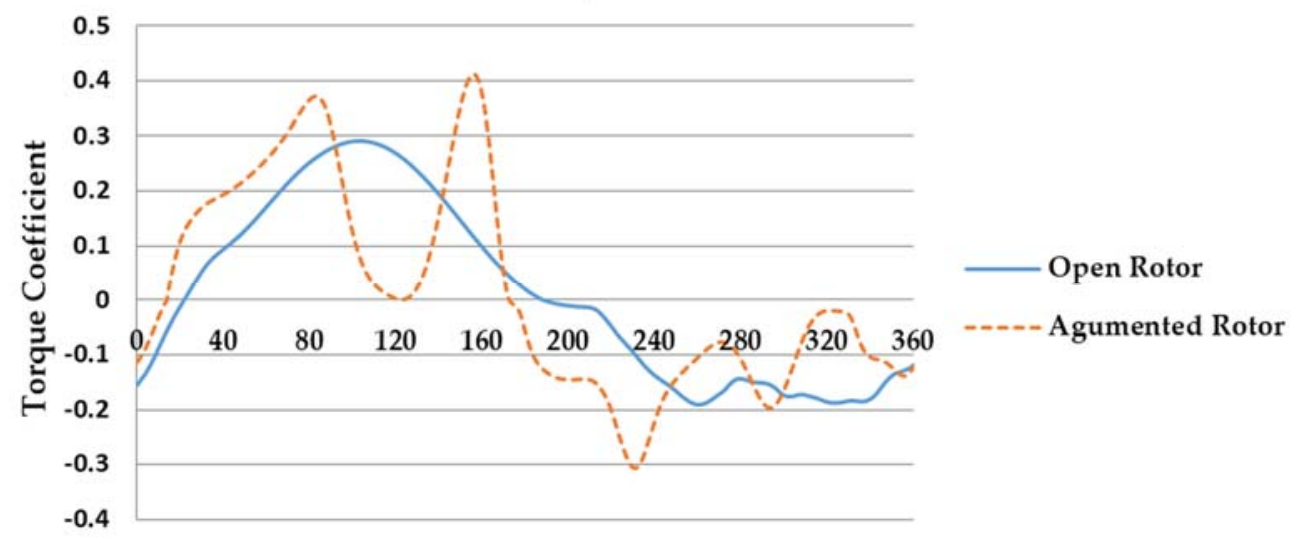

Azimuth Angle(deg)

Figure 24. Torque coefficient versus azimuth angle for open and augmented rotor for $\operatorname{TSR}=3$, $R_{\text {shape-ratio }}=0.55$. 
As can be seen from Figures 21-24 the second peak have been raised for TSR = 2 and TSR $=3$. Furthermore, the $C_{Q}$ of the open and augmented rotor have been measured at different TSR between 0 and 3. The results of this study are indicated by Figure 25.

$\mathrm{R}=0.55$

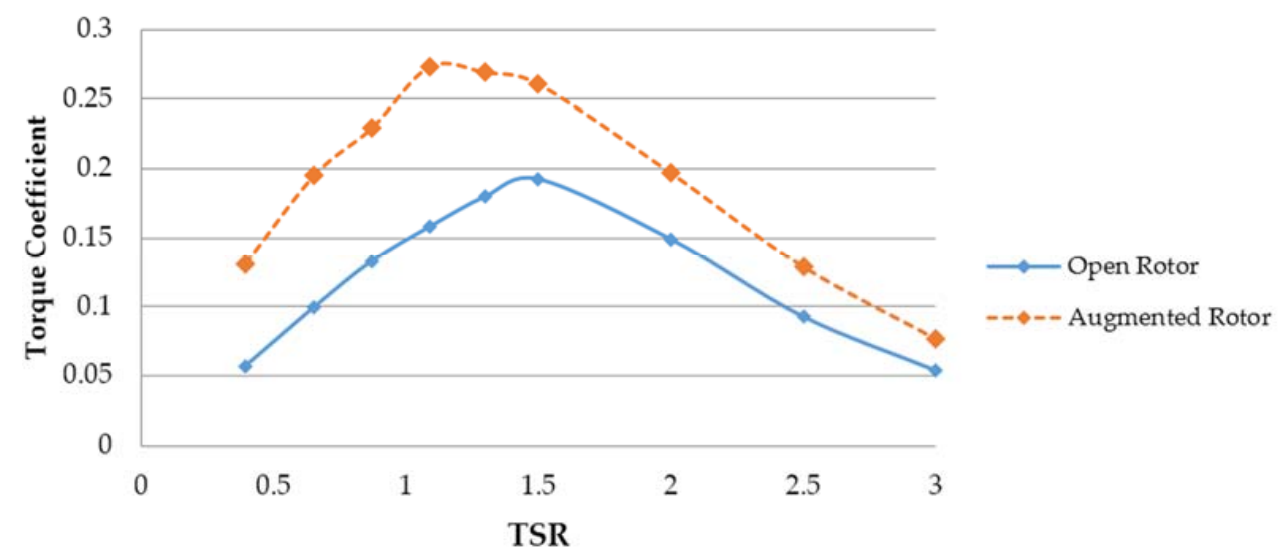

Figure 25. Torque coefficient versus TSR for open and augmented rotor.

The solid line represents torque coefficient of the VAWT while the dashed line shows the VAWT and ODGV together with shape ratio of the 0.55 . Although the highest $C_{Q}$ was observed for the open rotor when the TSR is 1.5 , for the augmented one it occurs at TSR $=1.3$. The maximum $C_{Q}$ of the open and augmented VAWT were 0.19 and 0.27 respectively. It can also be observed that results of the $C_{Q}$ for augmented rotor (by ODGV) have been improved by $58 \%$ compared to the open rotor. In the next step, power coefficient have been observed for open and augmented VAWT for different TSR between 0 and 3. The results of this study are illustrated in Figure 26.

\section{$\mathrm{R}=\mathbf{0 . 5 5}$}

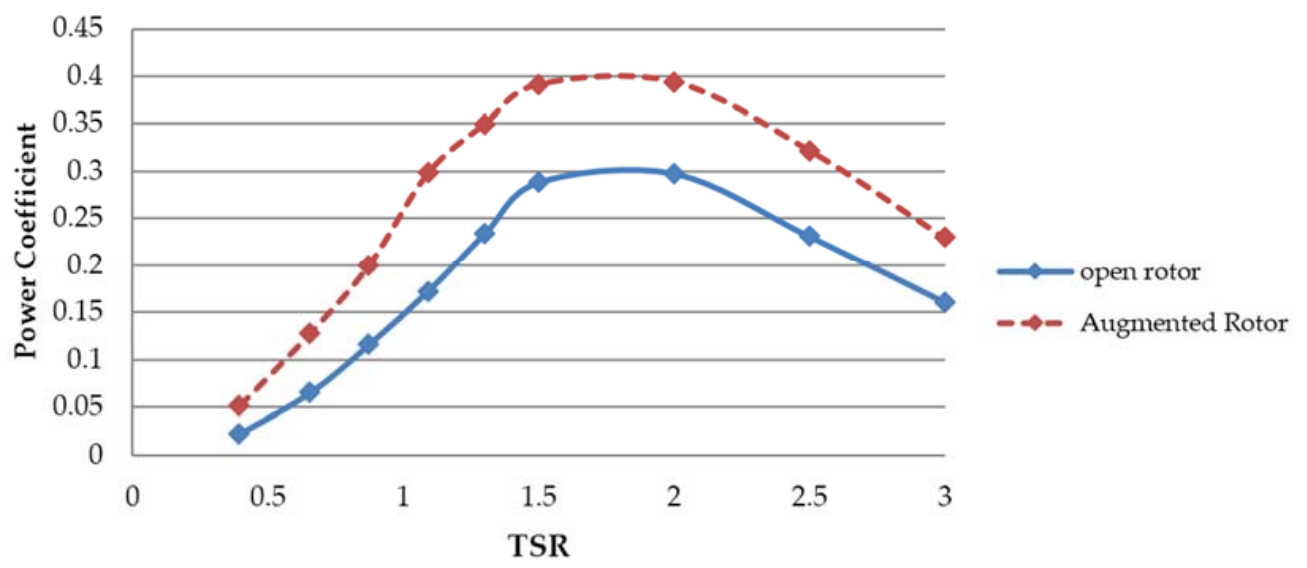

Figure 26. Power coefficient $C_{p}$ versus different TSR for open rotor and augmented rotor with shape ratio of the 0.55 .

It can be seen from Figure 26, ODGV can help to improve the $C_{p}$ in all ranges of the TSRs. The maximum $C_{p}$, as mentioned in the case 1, was achieved for the open rotor during the TSR of 1.5 to 2 . The same trend was reported for the augmented rotor by improving the average power coefficient around $48 \%$ compared to the open rotor.

\subsection{Case 3: ODGV with Different Shape Ratios}

The effect of the shape ratio of the ODGV on VAWT have been investigated in case 3. Eight different shape ratios between 0.3 and 0.7 , were tested in respect of the outer diameter of the ODGV. 
The biggest shape ratio is 0.3 with a diameter of $2333 \mathrm{~mm}$ and the smallest one is 0.7 with an outer diameter for the ODGV of $1000 \mathrm{~mm}$. The torque coefficient, power coefficient and velocity contour in different shape ratios were calculated in this step. Overall 72 simulations are conducted that among these simulation eight different shape ratios in nine different TSRs were simulated. Each simulation for the augmented rotor takes around $18 \mathrm{~h}$ and every simulation stabilizes and converges after ten revolutions. Figure 27 shows the $C_{Q}$ versus the azimuth angle for both the open and augmented rotor with different shape ratios.

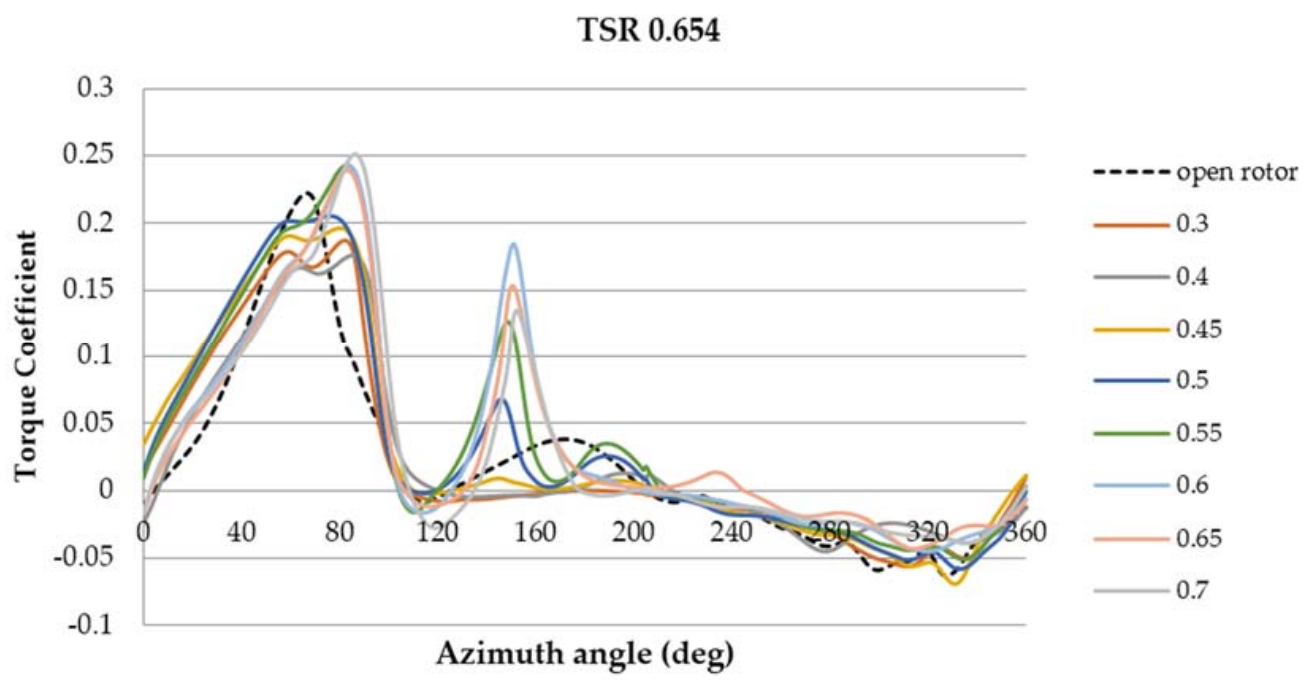

Figure 27. Torque coefficient versus azimuth angle in different shape ratios of the ODGV including the open rotor case.

As shown in Figure 27, the highest $C_{Q}$ is generated between the azimuth angles of $\theta=0^{\circ} 0$ to $\theta=105^{\circ}$. It can clearly be seen that the $C_{Q}$ for the shape ratios between 0.3 and 0.5 is lower than the open rotor, while $C_{Q}$ is higher than open rotor in the shape ratio between 0.7 and 0.55 . Between the azimuth angles $\theta=105^{\circ}$ and $\theta=205^{\circ}$ for the shape ratios of 0.7 to 0.5 , the peak for $C_{Q}$ is higher than the open rotor, while for 0.45 to 0.3 , this amount is lower. From the azimuth angles between $\theta=205^{\circ}$ and $\theta=360^{\circ}$, a positive effect on $C_{Q}$ can be reported for all shape ratios. In addition, the torque coefficient variations have been observed for different shape ratios (R) based on TSR between 0 and 3 . These results are illustrated by Figure 28 .

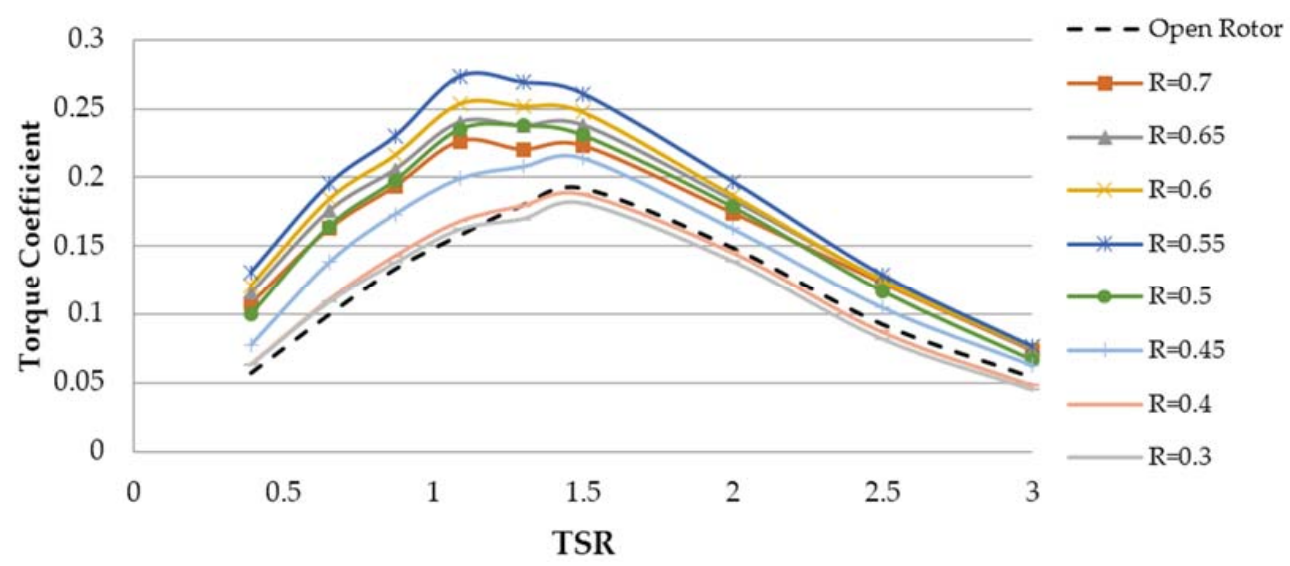

Figure 28. Average torque coefficient versus TSR for different shape ratios of the ODGV.

As can be seen from this figure, the shape ratios between 0.3 and 0.4 have a negative effect on the $C_{Q}$ after TSR of 1.2. The best performance was achieved by using the ODGV with the shape ratio 
of 0.55 , as indicated by a $58 \%$ overall enhancement in the averaged $C_{Q}$. However, between TSR of 2.5 to 3 , all of the shape ratios over 0.5 show a similar effect on the $C_{Q}$. Figure 29 also shows the power coefficient versus TSR for the open and augmented rotor.

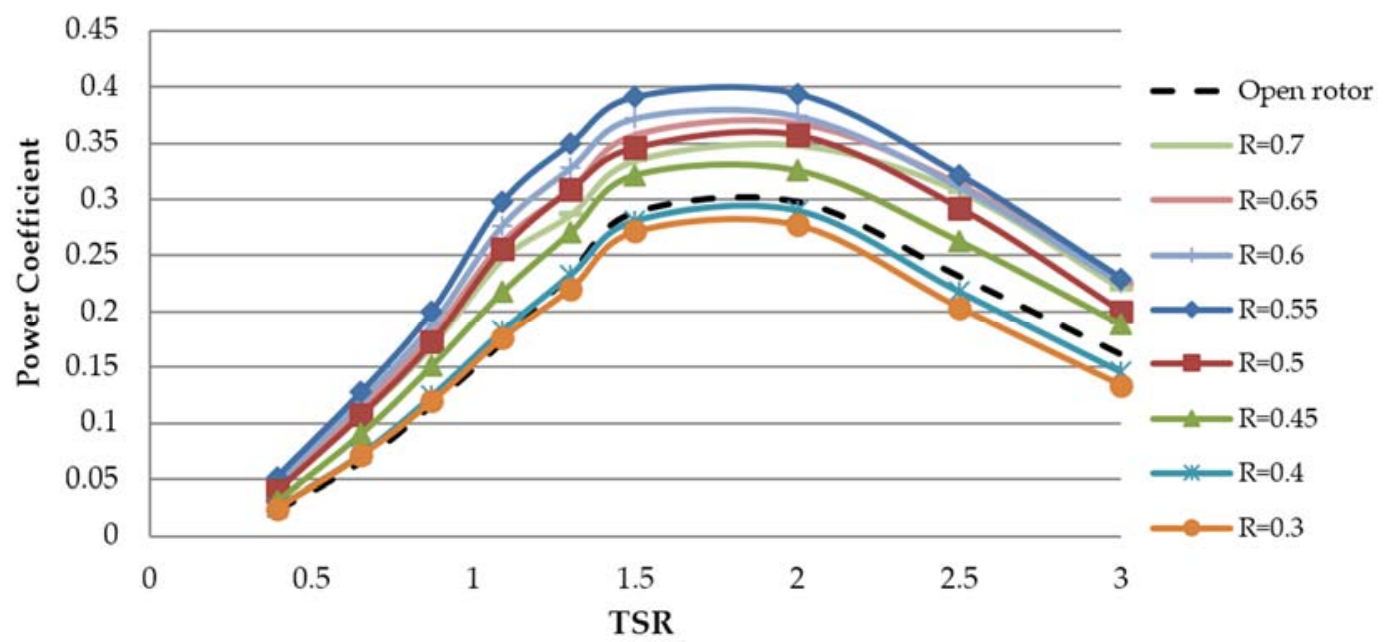

Figure 29. Power coefficient versus TSR for open and augmented rotors.

The trends of Figure 29 are identical to those of Figure 28, albeit at different rates. The highest $C_{p}$ for both the augmented and open rotor was reported at TSRs between 1.5 and 2 . The maximum $C_{p}$ values is 0.39 for the augmented rotor when the shape ratio is 0.55 . When it comes to the shape ratios of 0.3 and 0.4 similarly show a negative effect on the $C_{p}$ between TSRs of 1.3 and 3 . The shape ratios of 0.55, 0.6 and 0.65 have almost the same effect on the $C_{p}$ in TSRs higher than 2.5. In details, Figure 30 indicates the maximum $C_{P}$ enhancement provided by each shape ratio.

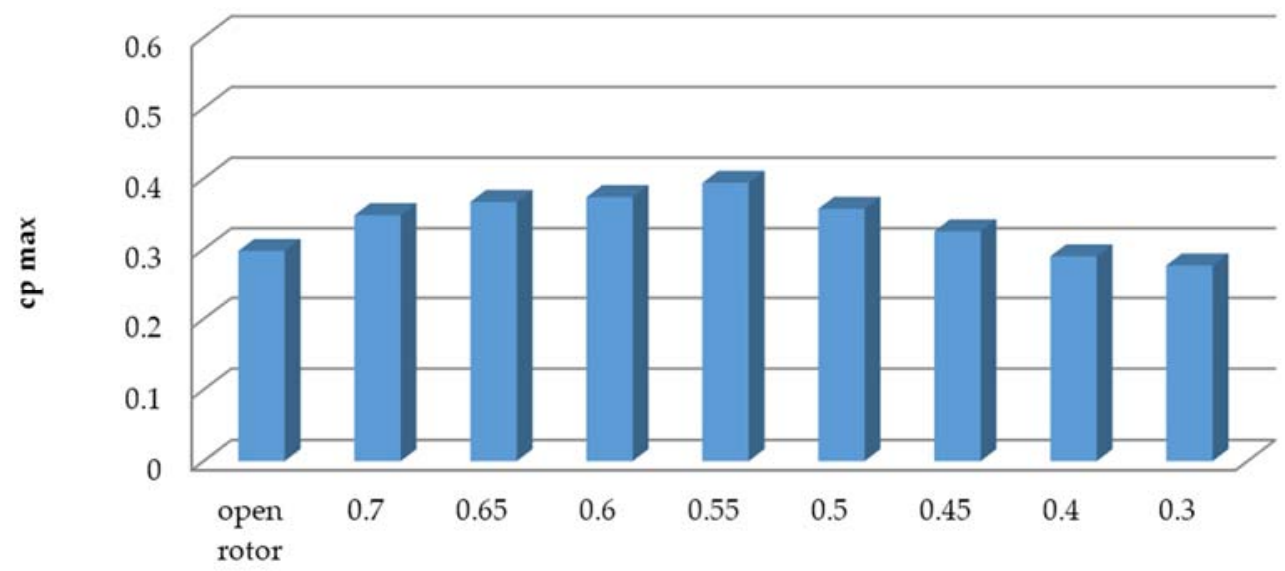

Figure 30. Variation of the maximum $C_{p}$ in different shape ratios.

The highest maximum $C_{P}$ was achieved when the shape ratio is 0.55 . Moreover, the power outputs have not been improved the shape ratios 0.4 and 0.3 , these values caused lower performance compared to an open rotor.

The effect of the ODGV on the flow behavior of the VAWT is shown in Figure 31. This result is achieved by using ODGV with a shape ratio of 0.55 at TSR $=0.654$ with a constant wind velocity of $6 \mathrm{~m} / \mathrm{s}$. A comparison between Figures 18 and 31 shows that in the augmented case, the size of the vortices behind the airfoils is significantly reduced. 


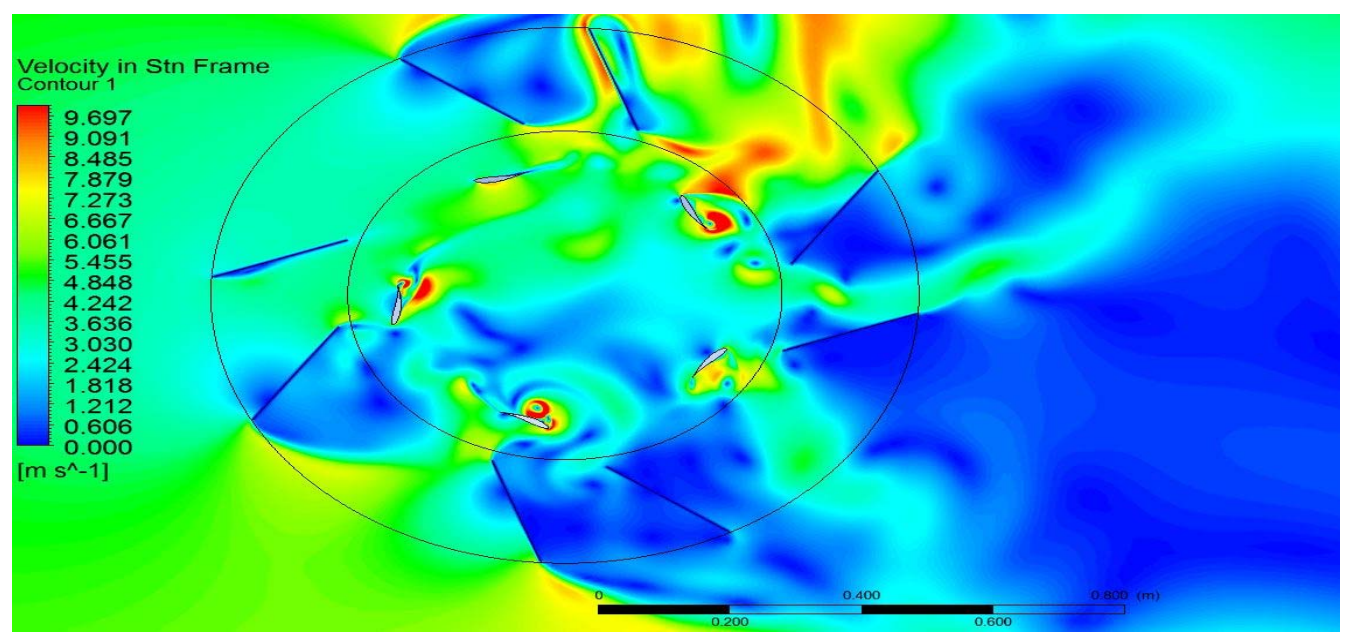

Figure 31. Contour of velocity magnitude for augmented rotor.

\subsection{Comparison with Previous Study Results}

The improvement of the average power and torque coefficients $\left(C_{P}\right.$ and $\left.C_{Q}\right)$ in this study has been compared with previous study wich has been conducted by Nobile et al. [13]. Figures 32 and 33 show comparisons of the power and torque coefficients, respectively.

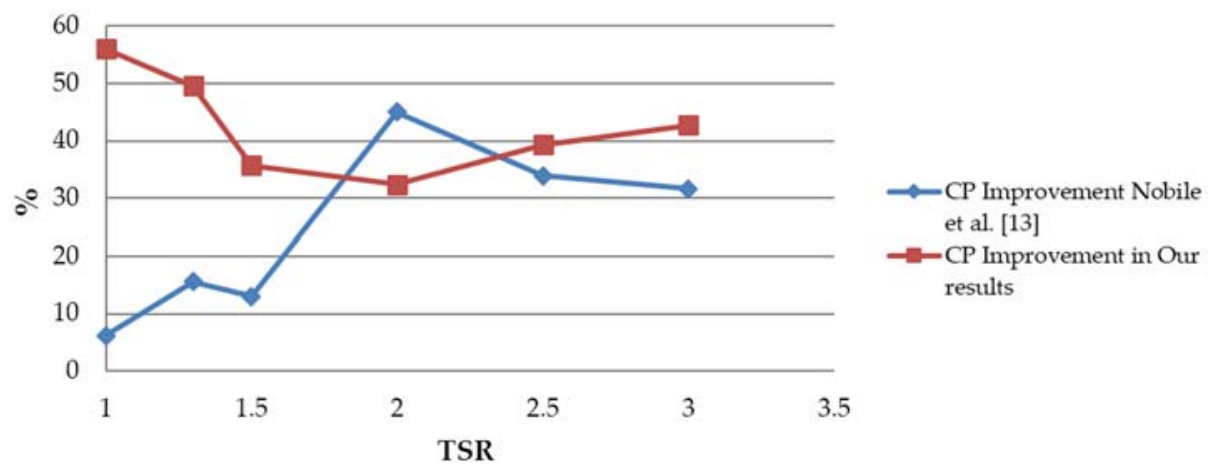

Figure 32. Comparison of the $C_{P}$ average improvement in this study with the Nobile et al. [13].

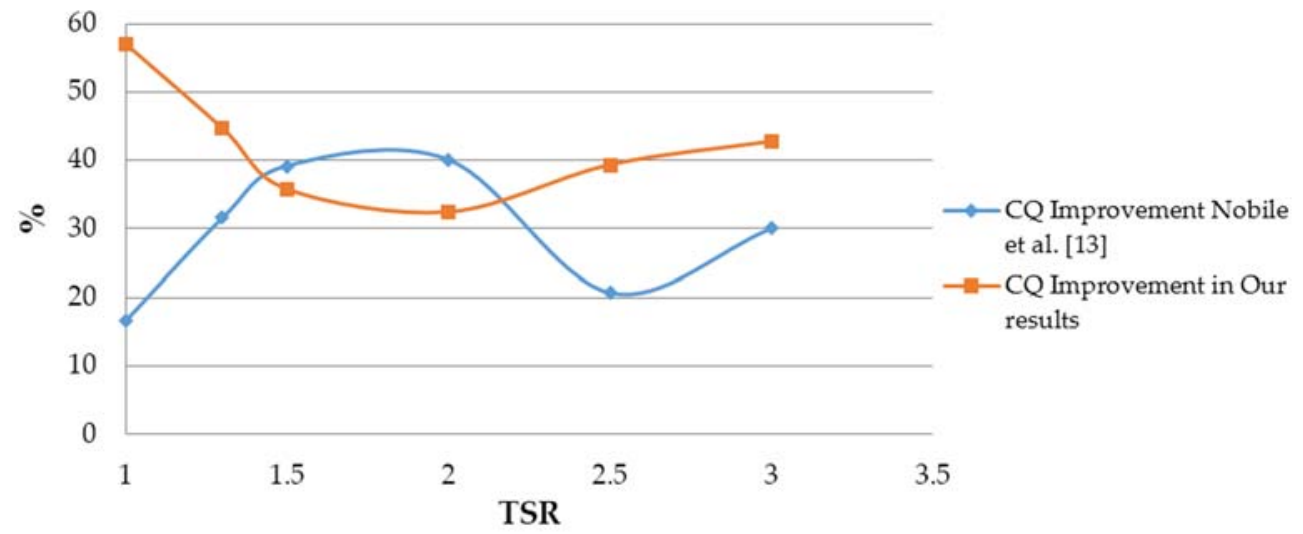

Figure 33. Comparison of the $C_{Q}$ average improvement in this study with the Nobile et al. [13].

\section{Discussion}

This study shows that the CFD tool can predict the flow behavior around the VAWT provided the turbulence model, mesh resolution and time step are carefully selected. The accuracy of the CFD was 
examined and compared with the experimental data to validate the CFD simulation. In addition, this study shows the effect of ODGV size on the VAWT.

As it can be seen from Figure 10, the size of the mesh is the most critical aspect of the CFD simulation to achieve accurate results. The cells or elements in the CFD simulation should be small around the boundary layers on the blades and ODGV walls to capture flow behavior. At the same time it should be sufficiently big to avoid over-resolving regions of little interest.

Validation of the CFD results in Figure 15 shows a good agreement between the experimental data and the CFD simulation. The overall differences between the experimental data and CFD results are due to the effects of the tip vortices are neglected in the 2-D simulation.

Definitely, choosing the proper turbulence model plays a significant role in CFD simulation. In this study, three different turbulence models; namely $k-\varepsilon$ model, $k-\omega$ and $k-\omega, S S T$, are examined to determine the best and most reliable turbulence model. Among these three models, $k-\omega$, SST has the best results in terms of accuracy. Even though, the simulation time was significantly decreased by using the $k-\varepsilon$ model, however the obtained results are not accurate enough owing to the fact that this model cannot precisely predict the flow the generated lift. Therefore, $k-\omega, S S T$ is selected for the successive analysis of the VAWT and ODGV.

A time dependency study was performed in order to reduce the simulation time without compromising the accuracy of the results. Three different time steps were examined; $0.5^{\circ} \omega^{-1}$, $1^{\circ} \omega^{-1}$ and $2^{\circ} \omega^{-1}$ (time for one degree equivalent rotation). Among these three time steps, $2^{\circ} \omega^{-1}$ was the worst case and there is a very small difference in the results for the $C_{m}$ between $0.5^{\circ} \omega^{-1}$ and $1^{\circ} \omega^{-1}$, therefore, a time step of $1^{\circ} \omega^{-1}$ was selected for the successive numerical simulations in order to reduce the computational time.

Three different cases including open rotor, augmented rotor with fixed shape ratio, and augmented rotor with different shape ratios have been simulated in this study. In the first case, the open rotor VAWT numerical simulation over a range of TSR magnitudes from 0.393 to 3 were performed to observe the variation in turbine performance with changing rotational speeds. The total torque and power coefficients in the mentioned TSRs are calculated.

In the second case, the power output of an augmented rotor was compared to an open rotor. This case investigates the ODGV effect on the VAWT in a constant shape ratio. In this case, the shape ratio for ODGV was fixed at 0.55 , so the outer diameter of the ODGV is $1272 \mathrm{~mm}$ and nine different TSRs for both VAWT and augmented rotor have been tested. The maximum torque coefficient for the augmented rotor was achieved when the azimuth angle is $\theta=85^{\circ}$ while for the open rotor it occurs at $\theta=60^{\circ}$. It was also observed that the average of torque coefficient has been increased by $58 \%$ when compared to the open rotor. The power coefficient $\left(C_{p}\right)$ was also reported and it shows that the $C_{p}$ has been improved by using ODGV in all ranges of the TSRs. The maximum $C_{p}$, as mentioned in case 1 , was achieved for the open rotor during the TSR of 1.5 to 2 . The same trend was reported for the augmented rotor by increasing the average power coefficient around $48 \%$ compared to the open rotor VAWT.

In case 3, the effect of the ODGV shape ratio on VAWT was investigated. Eight different shape ratios between 0.3 and 0.7 , which represent the outer diameter of the ODGV, were simulated. The biggest shape ratio is 0.3 with a diameter of $2333 \mathrm{~mm}$ and the smallest one is 0.7 with an outer ODGV diameter of $1000 \mathrm{~mm}$. Eight different shape ratios in nine different TSRs were simulated.

\section{Conclusions}

In this study, the performance of the VAWT with and without using ODGV was presented. In the first part of this study, an open rotor VAWT was examined in order to determine the best and proper mesh, turbulence model, and time step. The CFD results were validated by comparing with the experimental data. In the next step, the open rotor VAWT and augmented turbine were compared, and the performance of the augmented turbine was examined to present the torque and power coefficients. The results showed that using ODGV could increase the average power coefficient by up to $48 \%$. 
The last study in this paper concerned the effect of the shape ratio of the ODGV on the performance of the VAWT, in which 72 simulations were performed to determine the best shape ratio for nine different tip speed ratios. The results showed that except for the two shape ratios, 0.3 and 0.4 , all the other ratios had a positive effect on the coefficient of the power and torque. The results showed that a shape ratio of 0.55 had the highest improvement on the average power coefficient by $48 \%$ and the average torque coefficient by $58 \%$.

Acknowledgments: The authors would like to acknowledge the Ministry of Higher Education of Malaysia and The University of Malaya, Kuala Lumpur, Malaysia for the financial support under Research University Grants RP006C-13AET and UM.C/HIR/MOHE/ENG/15 (D000015-16001).

Author Contributions: B. Shahizare, S. Tabatabaeikia have and Nima Izadyar conceived CFD simulation, experimental study and writing of this article. N. Nik-Ghazali and W. T. Chong are the head of two groups in University of Malaya that guide all of the procedure.

Conflicts of Interest: The authors declare no conflict of interest.

\section{Nomenclature}

\begin{tabular}{ll}
\hline$A_{S}$ & Swept turbine area \\
$c$ & Blade chord length \\
$C_{Q}$ & Torque coefficient \\
$C_{Q, \text { ave }}$ & Average torque coefficient \\
$C_{P, \text { ave }}$ & Average power coefficient \\
$C_{P}$ & Power coefficient \\
$D_{R}$ & Turbine diameter \\
$\mathrm{H}$ & Height of the blade \\
HAWT & Horizontal axis wind turbine \\
LES & Large Eddy Simulation \\
$\mathrm{N}$ & Number of blades \\
ODGV & omni direction guide vane \\
$R_{\text {shape-ratio }}$ & Shape ratio of the ODGV \\
RANS & Reynolds Averaged Navier Stokes \\
$R_{\text {rotor }}$ & Rotor radius \\
SST & Shear Stress Transport \\
$t$ & Thickness of the blade \\
TSR & Tip speed ratio \\
$U_{\infty}$ & Relative wind speed \\
VAWT & Vertical axis wind turbine \\
$Y_{\text {plus }}$ & A non-dimensional wall distance for a wall-bounded flow \\
$\omega$ & Turbine angular velocity \\
$\theta$ & Azimuth angle \\
\hline
\end{tabular}

\section{References}

1. McLaren, K.W. A Numerical and Experimental Study of Unsteady Loading of High Solidity Vertical Axis Wind Turbines. Ph.D. Thesis, McMaster University, Hamilton, ON, Canada, October 2011.

2. Gharali, K.; Johnson, D.A. Numerical modeling of an $\mathbf{8} 809$ airfoil under dynamic stall, erosion and high reduced frequencies. Appl. Energy 2012, 93, 45-52. [CrossRef]

3. Hofemann, C.; Simao Ferreira, C.; van Bussel, G.; van Kuik, G.; Scarano, F.; Dixon, K. 3D Stereo PIV study of tip vortex evolution on a vawt. In Proceedings of the European Wind Energy Conference and Exhibition EWEC, Brussels, Belgium, 31 March-3 April 2008; European Wind Energy Association: Bruxelles, Belgium, 2008.

4. Mertens, S. Wind Energy in the Built Environment: Concentrator Effects of Buildings; Delft University of Technology: Delft, The Netherlands, 2006. 
5. Ferreira, C.S.; van Bussel, G.; van Kuik, G. 2D CFD simulation of dynamic stall on a vertical axis wind turbine: Verification and validation with PIV measurements. In Proceedings of the 45th AIAA Aerospace Sciences Meeting and Exhibit, Reno, NV, USA, 8-11 January 2007; pp. 1-11.

6. Chong, W.; Fazlizan, A.; Poh, S.; Pan, K.; Hew, W.; Hsiao, F. The design, simulation and testing of an urban vertical axis wind turbine with the omni-direction-guide-vane. Appl. Energy 2013, 112, 601-609. [CrossRef]

7. Chong, W.; Fazlizan, A.; Poh, S.; Pan, K.; Ping, H. Early development of an innovative building integrated wind, solar and rain water harvester for urban high rise application. Energy Build. 2012, 47, 201-207. [CrossRef]

8. Chong, W.; Naghavi, M.; Poh, S.; Mahlia, T.; Pan, K. Techno-economic analysis of a wind-solar hybrid renewable energy system with rainwater collection feature for urban high-rise application. Appl. Energy 2011, 88, 4067-4077. [CrossRef]

9. Chong, W.T.; Pan, K.C.; Poh, S.C.; Fazlizan, A.; Oon, C.S.; Badarudin, A.; Nik-Ghazali, N. Performance investigation of a power augmented vertical axis wind turbine for urban high-rise application. Renew. Energy 2013, 51, 388-397. [CrossRef]

10. Oman, R.; Foreman, K.; Gilbert, B.L. Investigation of Diffuser-Augmented Wind Turbines; Progress Report; Grumman Aerospace Corp.: Bethpage, NY, USA, 1976; p. 1.

11. Thomas, R.N. Vertical Windmill with Omnidirectional Diffusion. US Patent 5332925, 26 July 1994.

12. Wang, Y.F.; Zhan, M.S. Effect of barchan dune guide blades on the performance of a lotus-shaped micro-wind turbine. J. Wind Eng. Ind. Aerodyn. 2015, 136, 34-43. [CrossRef]

13. Nobile, R.; Vahdati, M.; Barlow, J.F.; Mewburn-Crook, A. Unsteady flow simulation of a vertical axis augmented wind turbine: A two-dimensional study. J. Wind Eng. Ind. Aerodyn. 2014, 125, 168-179. [CrossRef]

14. Danao, L.A.; Edwards, J.; Eboibi, O.; Howell, R. A numerical investigation into the influence of unsteady wind on the performance and aerodynamics of a vertical axis wind turbine. Appl. Energy 2014, 116, 111-124. [CrossRef]

15. Almohammadi, K.M.; Ingham, D.B.; Ma, L.; Pourkashan, M. Computational fluid dynamics (CFD) mesh independency techniques for a straight blade vertical axis wind turbine. Energy 2013, 58, 483-493. [CrossRef]

16. Pope, K.; Rodrigues, V.; Doyle, R.; Tsopelas, A.; Gravelsins, R.; Naterer, G.F.; Tsang, E. Effects of stator vanes on power coefficients of a zephyr vertical axis wind turbine. Renew. Energy 2010, 35, 1043-1051. [CrossRef]

17. Takao, M.; Kuma, H.; Maeda, T.; Kamada, Y.; Oki, M.; Minoda, A. A straight-bladed vertical axis wind turbine with a directed guide vane row-Effect of guide vane geometry on the performance. J. Therm. Sci. 2009, 18, 54-57. [CrossRef]

18. Edwards, J.M.; Danao, L.A.; Howell, R.J. Novel experimental power curve determination and computational methods for the performance analysis of vertical axis wind turbines. J. Sol. Energy Eng. 2012, 134, 031008. [CrossRef]

19. Danao, L.A.; Howell, R. Effects on the performance of vertical axis wind turbines with unsteady wind inflow: A numerical study. In Proceedings of the 50th AIAA Aerospace Sciences Meeting Including the New Horizons Forum and Aerospace Exposition, Nashville, TN, USA, 9-12 January 2012.

20. Amet, E.; MaÃŽtre, T.; Pellone, C.; Achard, J.L. 2D numerical simulations of blade-vortex interaction in a Darrieus turbine. J. Fluids Eng. 2009, 131, 111103. [CrossRef]

21. Aslam Bhutta, M.M.; Hayat, N.; Farooq, A.U.; Ali, Z.; Jamil, S.R.; Hussain, Z. Vertical axis wind turbine-A review of various configurations and design techniques. Renew. Sustain. Energy Rev. 2012, 16, 1926-1939. [CrossRef]

22. Balduzzi, F.; Bianchini, A.; Carnevale, E.A.; Ferrari, L.; Magnani, S. Feasibility analysis of a Darrieus vertical-axis wind turbine installation in the rooftop of a building. Appl. Energy 2012, 97, 921-929. [CrossRef]

23. Kang, C.; Liu, H.; Yang, X. Review of fluid dynamics aspects of Savonius-rotor-based vertical-axis wind rotors. Renew. Sustain. Energy Rev. 2014, 33, 499-508. [CrossRef]

24. Wekesa, D.W.; Wang, C.; Wei, Y.; Danao, L.A.M. Influence of operating conditions on unsteady wind performance of vertical axis wind turbines operating within a fluctuating free-stream: A numerical study. J. Wind Eng. Ind. Aerodyn. 2014, 135, 76-89. [CrossRef]

25. Shi, L.; Riziotis, V.; Voutsinas, S.; Wang, J. A consistent vortex model for the aerodynamic analysis of vertical axis wind turbines. J. Wind Eng. Ind. Aerodyn. 2014, 135, 57-69. [CrossRef] 
26. Alaimo, A.; Esposito, A.; Messineo, A.; Orlando, C.; Tumino, D. 3D CFD Analysis of a Vertical Axis Wind Turbine. Energies 2015, 8, 3013-3033. [CrossRef]

27. Hasan, M.R.; Islam, M.R.; Hasan Shahariar, G.; Mashud, M. Numerical analysis of vertical axis wind turbine. In Proceedings of the IEEE 9th International Forum on Strategic Technology, Cox's Bazar, Bangladesh, 21-23 October 2014; pp. 318-321.

28. Howell, R.; Qin, N.; Edwards, J.; Durrani, N. Wind tunnel and numerical study of a small vertical axis wind turbine. Renew. Energy 2010, 35, 412-422. [CrossRef]

29. De Marco, A.; Coiro, D.P.; Cucco, D.; Nicolosi, F. A Numerical Study on a Vertical-Axis Wind Turbine with Inclined Arms. Int. J. Aerosp. Eng. 2014, 2014. [CrossRef]

30. Coiro, D.; Nicolosi, F.; de Marco, A.; Melone, S.; Montella, F. Flow Curvature Effect on Dynamic Behaviour of a Novel Vertical Axis Tidal Current Turbine: Numerical and Experimental Analysis. In Proceedings of the ASME 24th International Conference on Offshore Mechanics and Arctic Engineering, Halkidiki, Greece, 12-17 June 2005; American Society of Mechanical Engineers: New York, NY, USA, 2005; pp. 601-609.

31. Paillard, B.; Astolfi, J.A.; Hauville, F. URANSE simulation of an active variable-pitch cross-flow Darrieus tidal turbine: Sinusoidal pitch function investigation. Int. J. Mar. Energy 2015, 11, 9-26. [CrossRef]

32. Fluent, A. 12.0 Theory Guide; Ansys Inc.: Cecil Township, PA, USA, 2009; p. 5.

33. Mohamed, M.H.; Ali, A.M.; Hafiz, A.A. CFD analysis for H-rotor Darrieus turbine as a low speed wind energy converter. Eng. Sci. Technol. Int. J. 2015, 18, 1-13. [CrossRef]

34. Pope, A.; Harper, J.J. Low Speed Wind Tunnel Testing; John Wiley \& Sons: New York, NY, USA, 1966.

35. Wang, S.; Ingham, D.B.; Ma, L.; Pourkashanian, M.; Tao, Z. Numerical investigations on dynamic stall of low Reynolds number flow around oscillating airfoils. Comput. Fluids 2010, 39, 1529-1541. [CrossRef]

36. McLaren, K.; Tullis, S.; Ziada, S. Computational fluid dynamics simulation of the aerodynamics of a high solidity, small-scale vertical axis wind turbine. Wind Energy 2012, 15, 349-361. [CrossRef]

37. Raciti Castelli, M.; Englaro, A.; Benini, E. The Darrieus wind turbine: Proposal for a new performance prediction model based on CFD. Energy 2011, 36, 4919-4934. [CrossRef]

38. Chen, C.C.; Kuo, C.H. Effects of pitch angle and blade camber on flow characteristics and performance of small-size Darrieus VAWT. J. Vis. 2013, 16, 65-74. [CrossRef]

39. Guerri, O.; Sakout, A.; Bouhadef, K. Simulations of the fluid flow around a rotating vertical axis wind turbine. Wind Eng. 2007, 31, 149-163. [CrossRef]

40. Dai, Y.; Lam, W. Numerical study of straight-bladed Darrieus-type tidal turbine. Proc. ICE Energy 2009, 162, 67-76. [CrossRef]

41. Gupta, R.; Biswas, A. Computational fluid dynamics analysis of a twisted three-bladed H-Darrieus rotor. J. Renew. Sustain. Energy 2010, 2, 043111. [CrossRef]

42. Maître, T.; Amet, E.; Pellone, C. Modeling of the flow in a Darrieus water turbine: Wall grid refinement analysis and comparison with experiments. Renew. Energy 2013, 51, 497-512. [CrossRef]

43. Qin, N.; Howell, R.; Durrani, N.; Hamada, K.; Smith, T. Unsteady flow simulation and dynamic stall behaviour of vertical axis wind turbine blades. Wind Eng. 2011, 35, 511-528. [CrossRef]

44. Mohamed, M.H. Performance investigation of H-rotor Darrieus turbine with new airfoil shapes. Energy 2012, 47, 522-530. [CrossRef]

(c) 2016 by the authors; licensee MDPI, Basel, Switzerland. This article is an open access article distributed under the terms and conditions of the Creative Commons by Attribution (CC-BY) license (http://creativecommons.org/licenses/by/4.0/). 